Research Article

\title{
Green Synthesis of Silver Nanoparticles Using Catharanthus roseus Flower Extracts and the Determination of Their Antioxidant, Antimicrobial, and Photocatalytic Activity
}

\author{
Mathivathani Kandiah (D) and Kavishadhi N. Chandrasekaran (iD) \\ BMS School of Science, 591 Galle Road, Colombo 06, Sri Lanka \\ Correspondence should be addressed to Mathivathani Kandiah; mathi@bms.edu.lk
}

Received 9 January 2021; Revised 12 April 2021; Accepted 19 May 2021; Published 29 May 2021

Academic Editor: Eduard Llobet

Copyright (c) 2021 Mathivathani Kandiah and Kavishadhi N. Chandrasekaran. This is an open access article distributed under the Creative Commons Attribution License, which permits unrestricted use, distribution, and reproduction in any medium, provided the original work is properly cited.

\begin{abstract}
The present study describes the antioxidant, antimicrobial, and photocatalytic activity of silver nanoparticles (AGNPs) synthesized using six varieties of Catharanthus roseus flower extracts for the first time. Initially, the synthesized AgNPs were visually confirmed by color change. Further, the formation, size, and shape of the synthesized AgNPs were characterized by UV-Vis spectroscopy and scanning electron microscopy (SEM). The SEM image of purple flower AgNPs and the calculated bandgap energies of the synthesized AgNPs showed that the synthesized AgNPs were in the range of 0-30 nm. Qualitative phytochemical analysis revealed the presence of the phytocompounds that were responsible for the capping, formation, bioreduction, and stabilization of AgNPs. The antioxidant ability of the AgNPs and their respective flower extracts were analyzed using TFC, TPC, TAC, DPPH, FRAP, and IC50 assays. The results of the antioxidant assays indicated that the AgNPs showed higher antioxidant activity compared to their respective flower extracts. The synthesized AgNPs showed significant antimicrobial activity against Gram-negative Escherichia coli compared to Gram-positive Staphylococcus aureus assayed using the agar well diffusion method. Furthermore, the photocatalytic activity of the synthesized purple flower AgNPs at two different concentrations $5000 \mathrm{ppm}$ and $333 \mathrm{ppm}$ was analyzed by the removal of methyl orange dye from an aqueous solution under sunlight irradiation in the presence of $\mathrm{NaBH} 4$ catalyst. Results indicated that $333 \mathrm{ppm}$ purple flower AgNPs exhibited an efficient photocatalytic activity in the degradation of methyl orange compared to 5000 ppm purple flower AgNPs in 20 minutes. Thus, the results obtained indicated that Catharanthus roseus is an ecofriendly source for the green synthesis of AgNPs which can be used as a novel antioxidant, antimicrobial, and photocatalytic agent; thereby, it can be used in a variety of applications to improve the quality of human life.
\end{abstract}

\section{Introduction}

Nanotechnology is a developing field of research involving the design, fabrication, characterization, and application of particles, materials, or systems in the nanoscale due to the unique size-dependent physical and chemical properties [1]. One of the key areas most attention is drawn to is the synthesizing of different metal nanoparticles [2]. Nanoparticles are microscopic particles with at least one dimension in the nanoscale which is $1-100 \mathrm{~nm}$ [3].

In this study AgNPs are synthesized as silver unlike other metals such as copper, gold, and nickel that have an increasing interest due to properties such as localized surface plasma resonance, chemical stability, catalytic activity, high conductivity, and cost-effectiveness compared to synthesizing nanoparticles from metals such as gold. Besides AgNPs have proven to be less toxic to mammalian cells than other nanoparticles [4].

Due to their surface plasmon resonance properties, AgNPs are used in sensors like fluorescence sensors, colorimetric sensors, and surface-enhanced Raman spectrometry sensors to detect pollutants in the environment. Similarly, due to their antimicrobial and properties, AgNPs can easily penetrate cells through the cell membrane and serve as an antimicrobial agent; therefore, it is used in the treatment of microbes and is also used in coating surgical 
devices [5]. Furthermore due to the smaller size of AgNPs which contain high number of surface active sites and faster spatial charge, increase in the photocatalytic activity against pollutants such as azo dyes is proved. [6].

Although many nanoparticles are synthesized over the past few years using conventional physical and chemical methods, only a few of them are currently used as these methods use harmful chemicals and produce byproducts that are toxic to the environment. Furthermore, these nanoparticles synthesized from these methods cannot be used especially in clinical fields due to the lack of knowledge about health-related issues and toxicity [7]. Therefore, a bottom-up approach "green synthesis" method has been developed as a substitute to defeat the limitations and challenges of the conventional methods (Figure 1).

Green synthesis is the utilization of biological extracts such as plants or microorganisms to synthesize nanoparticles (Figure 2). Plant-mediated green synthesis approaches are more favorable and are mainly focused on the current research and fabrication advances since using microorganisms are biohazardous, require special isolation techniques, and are more prone to contaminations [9].

In the green synthesis of metal nanoparticles, the plant extract is mixed with a metal salt solution. Using phytochemicals present in the plant extracts in different combinations and concentrations including other factors such as $\mathrm{pH}$ of the reaction mixture, temperature, concentration, pressure, and reaction time, the electrochemical potential of a metal ion a biochemical reduction takes place.

During this reaction, the metal ions are converted from their mono/divalent state to a zero-valent state followed by nucleation and growth to form metal nanoparticles (Figure 3). Recent studies reported that various plants contain an extensive range of phytochemicals such as phenols and enzymes that contain important functional groups including hydroxyl and carboxyl which potentially can act as reducing, capping, and stabling agents [10].

In this study, the flower extracts of Catharanthus roseus were used to synthesize nanoparticles as previous studies have shown Catharanthus roseus extracts possess a good antioxidant property due to the presence of various polyphenols identified [11] (Figure 4).

Catharanthus roseus of the family Apocynaceae is commonly known as periwinkle which is grown as an ornamental flowering plant [12]. Flowers are pentamerous, actinomorphic with variations of colors (white, purple, peach, pink, scarlet, and red) [13]. Different parts of the plant are found to be used worldwide for different purposes. In Sri Lanka, it is widely used in Ayurvedic medicine to treat a variety of diseases. Researchers investigated for the medical properties have discovered the presence of two phytochemicals, Vinblastine and vincristine, which can be used as chemotherapeutics drugs [14].

Free radicles are molecules with an unpaired electron in the outer shell that are highly unstable, so they tend to react with organic substrates such as DNA and lipids in the body [15]. In humans, free radicles in excess, generate oxidative stress damaging cell structures which are a risk factor in many diseases such as cancer and neurodegenerative diseases [16].
There are several mechanisms in the body to counter react oxidative stress using antioxidants which are naturally occurring in the body or taken via diet. Studies show that nanoparticles synthesized from various natural sources rich in antioxidants can act as free radical scavengers to replace harmful synthetic antioxidants such as butylated hydroxyanisole (BHA) and butylated hydroxytoluene (BHT) [17].

Furthermore, the disposal of organic dyes such as methyl orange is a crucial problem in textile and paper industries since they are nondegradable under normal conditions due to the presence of strong azo bonds (Figure 5) [18]. Studies report that the removal of organic dyes using AgNPs is a better alternative option than the common dye removal techniques like redox treatments since it does not produce any harmful byproducts [19].

The aim of this research is to synthesize ecofriendly AgNPs using six varieties of Catharanthus roseus flower extracts and to access their antioxidant, antimicrobial, and photocatalytic activity. The antioxidant activity will be determined using TFC, TPC, TAC, DPPH, FRAP, and IC50 assays. The antimicrobial activity will be determined against a Gram-negative and Grampositive bacterium, Escherichia coli and staphylococcus aureus, respectively, and the photocatalytic activity will be analyzed by the removal of methyl orange dye. By achieving all the objectives, the AgNPs can be a useful way for recycling flower wastes, treating free radical-mediated diseases, and making a better environment free from hazardous azo dyes.

\section{Materials and Methods}

\subsection{Materials}

2.1.1. Reagents. Acetic acid (CH3COOH) (CAS-7758-99-8), aluminium chloride (AlCl3) (CAS-7446-70-0), ammonium hydroxide $\left(\mathrm{NH}_{4} \mathrm{OH}\right)$, ammonium molybdate $\left(\left[\mathrm{NH}_{4}\right]_{6}\right.$ $\mathrm{Mo}_{24} \cdot 4 \mathrm{H} 2 \mathrm{O}$ ), chloroform $\left(\mathrm{CH}_{3} \mathrm{Cl}\right)$ (CAS-67-66-3), copper sulphate $\left(\mathrm{CuSO}_{4}\right)$ (CAS-7758-98-7), 2, 2-diphenyl-1- picrylhydrazyl (DPPH) (CAS-1898-66-4), ethanol $\left(\mathrm{C}_{2} \mathrm{H}_{5} \mathrm{OH}\right)$ (CAS- 64-17-5), ferric chloride $\left(\mathrm{FeCl}_{3}\right)$ (CAS-7705-08-0), Folin-Ciocalteu phenol reagent, methanol $\left(\mathrm{CH}_{3} \mathrm{OH}\right)(\mathrm{CAS}-67-$ 56-1), hydrochloric acid (HCl) (CAS-7647-01-01-0), McFarland solution, , methylene orange $\left(\mathrm{C}_{14} \mathrm{H}_{14} \mathrm{~N}_{3} \mathrm{NaO}_{3} \mathrm{~S}\right)$ (547-58-0), Molisch's reagent, Mueller-Hinton agar powder, nutrient agar powder, saline, silver nitrate $\left(\mathrm{AgNO}_{3}\right)$ (CAS-7761-88-8), sodium acetate $\left(\mathrm{CH}_{3} \mathrm{OONa}\right)$ (CAS $\left.127-09-3\right)$, sodium borohydride $\left(\mathrm{NaBH}_{4}\right)$, sodium carbonate $\left(\mathrm{Na}_{2} \mathrm{CO}_{3}\right)$ (CAS-497-19-8), sodium hydroxide $(\mathrm{NaOH})$ (CAS 1310-73-2), sodium nitrate $\left(\mathrm{NaNO}_{3}\right)(\mathrm{CAS} 7631-99-4)$, sodium sulphate $\left(\mathrm{Na}_{2} \mathrm{SO}_{4}\right)$ (CAS7757-82-6), sulphuric acid $\left(\mathrm{H}_{2} \mathrm{SO}_{4}\right)$ (CAS-7664-93-9), and 2, 4, 6-Tris(2-pyridyl)-s-triazine (TPTZ) (CAS-7757-82-6).

2.1.2. Instrumentation. Hot-air oven (meditry DHA9053A), incubator, analytical balance, spectrophotometer (JENWAY 6305), roller mixer, micropipettes, refrigerator, fume hood (Biobased FH1000), and autoclave.

2.1.3. Glassware and Miscellaneous. Conical flask, measuring cylinder, filter funnel, spatulas, test tubes, cuvettes, 


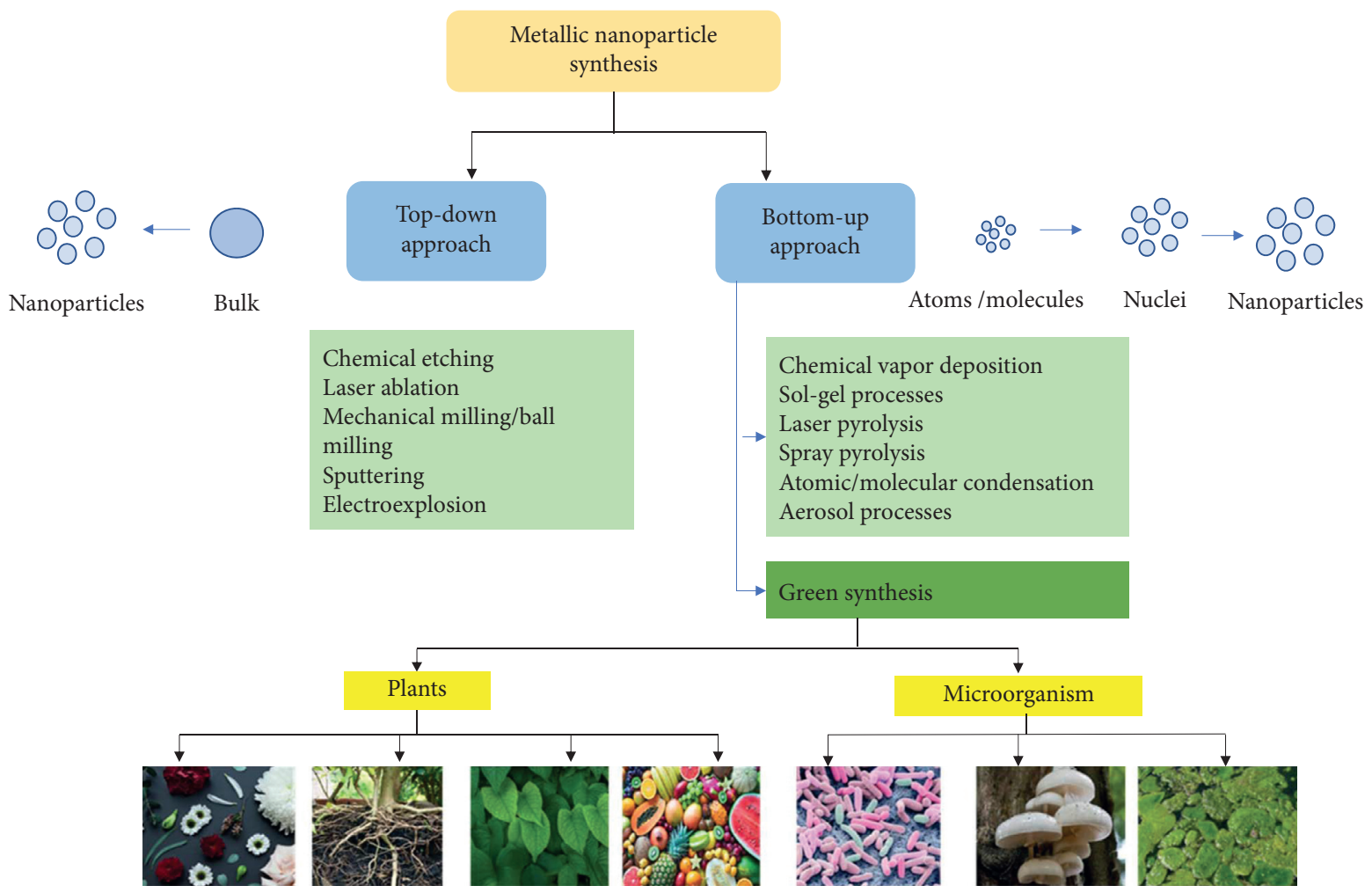

FIGURE 1: The two approaches and methods of nanoparticle synthesis [8].

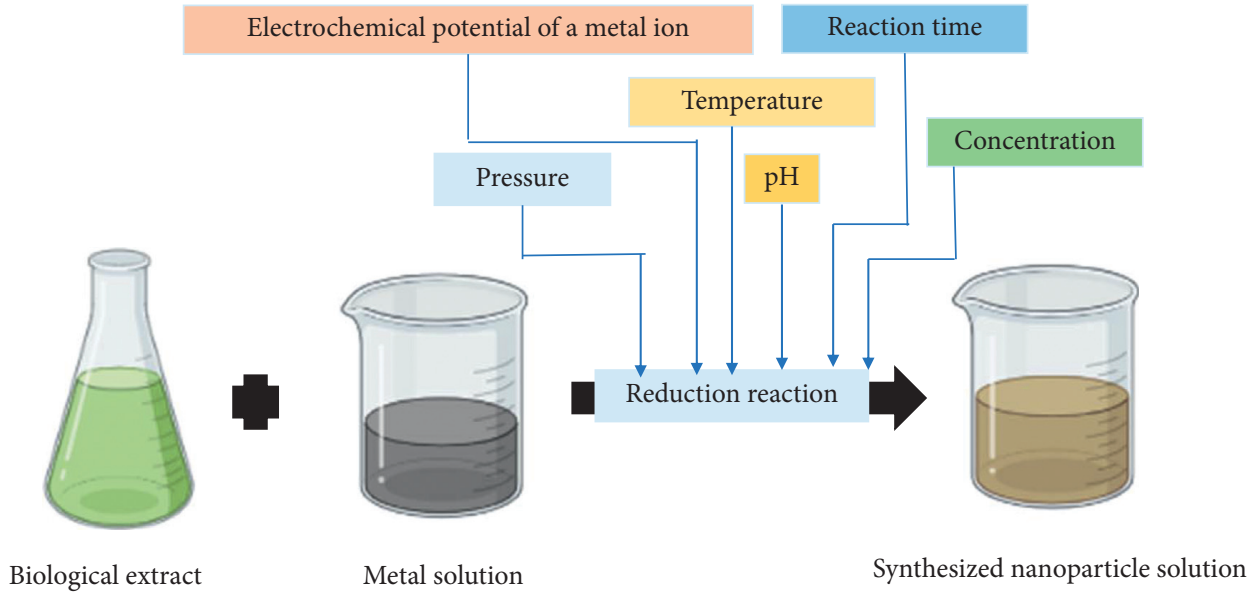

FIgURE 2: Basic steps of the green synthesis method.

volumetric flask, Petri dishes, beakers, cotton swabs, watch glass, filter paper, falcon tubes, and Whatman filter papers No.1.

2.2. Sample Collection. Five varieties of Catharanthus roseus flowers (Figure 6) were collected from Diyatha Uyana plant nursery, Battaramulla, Sri Lanka.

\subsection{Preparation of Flower Extracts Using Distilled Water.} The samples were air-dried and grounded into smaller pieces. To $2 \mathrm{~g}$ of each grounded sample, $40 \mathrm{~mL}$ of distilled water was added. The samples were incubated at $60^{\circ} \mathrm{C}$ for $30 \mathrm{~min}$ and were filtered using Whatman filter paper No.1 into $50 \mathrm{~mL}$ falcon tubes. The samples were stored at $4^{\circ} \mathrm{C}$ until further use.

2.4. Green Synthesis of AgNPs. $1 \mathrm{~mL}$ of each water extract was mixed with $9 \mathrm{~mL}$ of $\mathrm{AgNO}_{3}$ solution and was kept at room temperature (RT) for 3 days. The color change of the samples was observed, and the absorbance was measured from 300 to $620 \mathrm{~nm}$ using distilled water as a blank.

2.5. SEM and Particle Size Analysis. $10 \mathrm{~mL}$ of PF AgNPs was centrifuged at $5000 \mathrm{rpm}$ for $10 \mathrm{~min}$ and was transferred to wash glass. The sample added to the watch glass was dried 


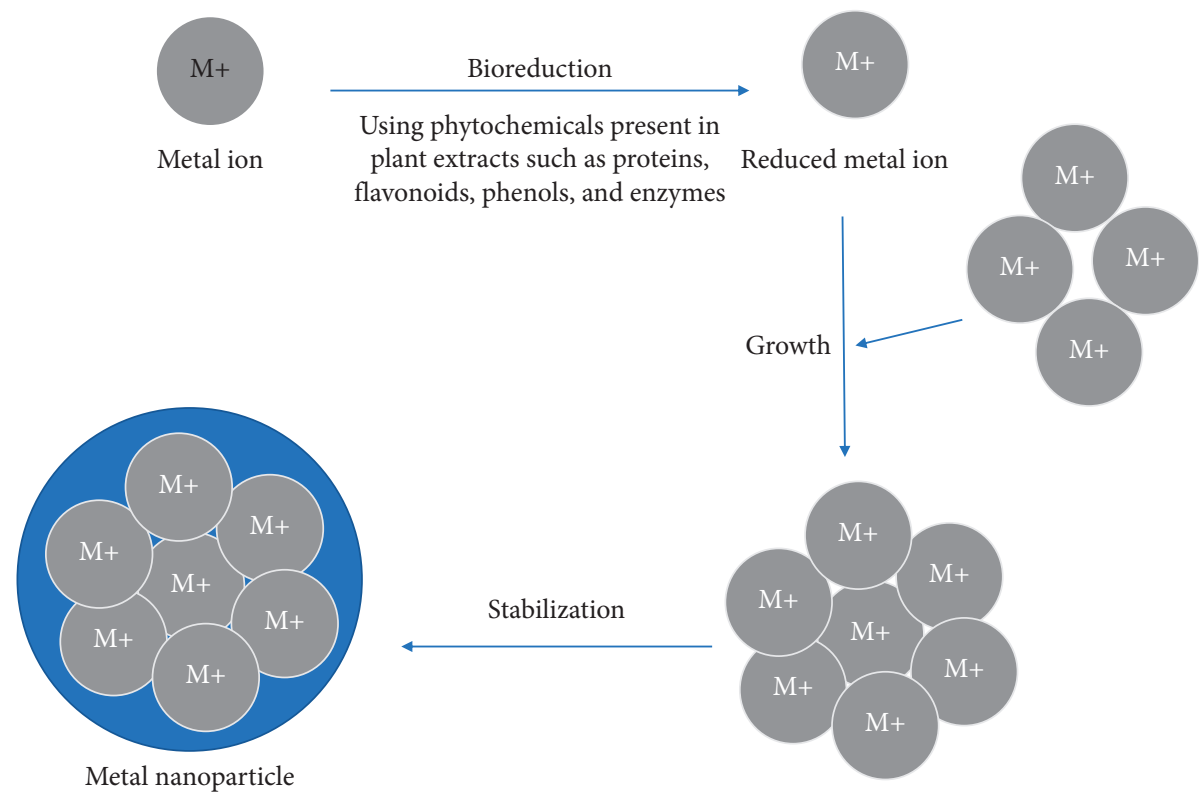

Figure 3: Mechanism of AgNPs green synthesis.

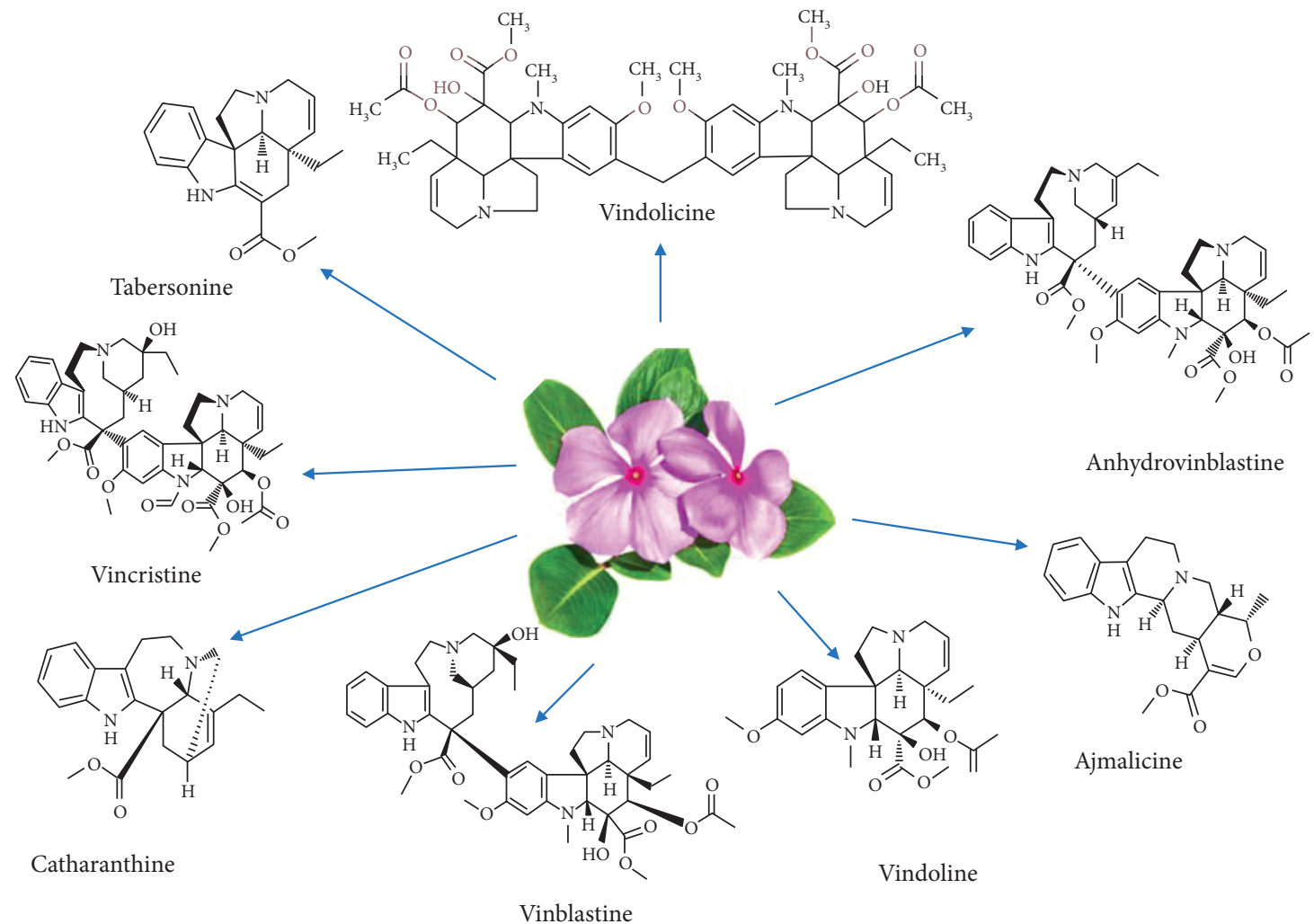

FIGURE 4: Antioxidants produced by Catharanthus roseus [12].

completely at $180^{\circ} \mathrm{C}$. The dried smear was dissolved by adding $200 \mu \mathrm{L}$ of distilled water and transferred into an Eppendorf tube. The sample was wrapped using aluminum foil and was sent for the SEM analysis. The morphology of PF AgNPs was examined using a Scanning Electron Microscope and the average particle size was analyzed by the Malvern Zetasizer Nano ZS particle size analyzer from the Sri Lanka
Institute of Nanotechnology (SLINTEC) using the Hitachi SU6600 SEM.

2.6. Phytochemical Analysis. The phytochemical analysis was carried out according to the methodologies shown in Table 1. 


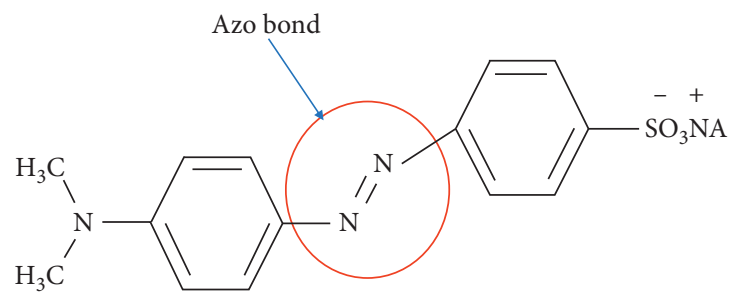

Figure 5: Structure of methyl orange. Methyl orange is an orange organic dye that contains a strong azo bond that is not degradable under normal conditions commonly used in titrations as a $\mathrm{pH}$ indicator and textile industries for dyeing and printing.

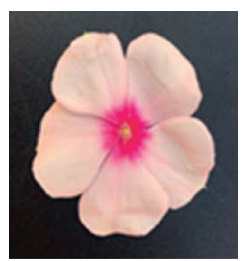

(LPF)

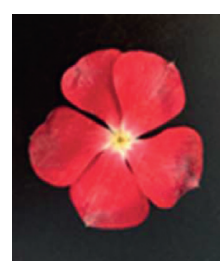

$(\mathrm{RF})$

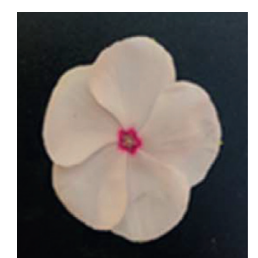

(WPF)

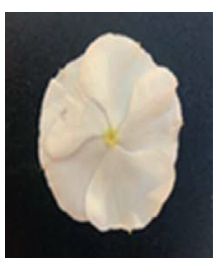

(WYF)

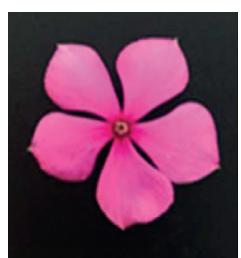

(PF)

(e)

FIGURE 6: Five varieties of Catharanthus roseus flowers and their code names. (LPF) Light pink (a), (RF) red (b), (WPF) white pink dot (c), (WYF) white yellow dot (d), and (PF) purple (e).

TABLE 1: Methodology of the phytochemical analysis [20].

\begin{tabular}{|c|c|c|}
\hline Phytochemical & Methodology & Expected positive color result \\
\hline Carbohydrates & $\begin{array}{l}2 \mathrm{ml} \text { of extract was treated with } 1 \mathrm{~mL} \text { of Molisch's reagent and a few drops of } \\
\text { concentrated } \mathrm{H}_{2} \mathrm{SO}_{4} \text { were added }\end{array}$ & $\begin{array}{l}\text { Formation of purple or reddish } \\
\text { color ring }\end{array}$ \\
\hline Tannins & $1 \mathrm{~mL}$ of extract was added to $2 \mathrm{~mL}$ of $5 \% \mathrm{FeCl}_{3}$ & $\begin{array}{l}\text { Formation of dark blue or greenish- } \\
\text { black color }\end{array}$ \\
\hline Saponins & $\begin{array}{l}2 \mathrm{~mL} \text { of extract and distilled water was added and shaken in a graduated cylinder } \\
\text { for } 15 \text { minutes }\end{array}$ & Formation of $1 \mathrm{~cm}$ layer of foam \\
\hline Terpenoids & $\begin{array}{l}0.5 \mathrm{~mL} \text { of the extract was treated with } 2 \mathrm{~mL} \text { of chloroform and concentrated } \\
\qquad \mathrm{H}_{2} \mathrm{SO}_{4}\end{array}$ & $\begin{array}{l}\text { Formation of red-brown color at the } \\
\text { interface }\end{array}$ \\
\hline Anthraquinones & Few drops of $10 \% \mathrm{NH}_{4} \mathrm{OH}$ were added to $1 \mathrm{~mL}$ of extract & $\begin{array}{l}\text { Formation of a pink color } \\
\text { precipitate }\end{array}$ \\
\hline Steroids & $\begin{array}{c}\text { To } 1 \mathrm{~mL} \text { of extract, an equal volume of chloroform was added and a few drops of } \\
\text { concentrated } \mathrm{H}_{2} \mathrm{SO}_{4}\end{array}$ & Formation of a brown color ring \\
\hline Proteins & To $1 \mathrm{~mL}$ of extract, a few drops of $\mathrm{CuSO}_{4}$ and $1 \mathrm{~mL}$ of $10 \% \mathrm{NaOH}$ were added & Formation of purple or mauve color \\
\hline
\end{tabular}

2.7. Determination of Antioxidant Activity. AgNPs and the water extracts were diluted $1: 15$ to analyze the antioxidant activity. Each analysis was carried out in triplicate.

2.7.1. Determination of Total Flavonoid Content (TFC). TFC was determined using an $\mathrm{AlCl}_{3}$ colorimetric method adopted from Perera and Kandiah [21]. $1.5 \mathrm{~mL}$ of the sample was mixed with $1.5 \mathrm{~mL}$ of $2 \% \mathrm{AlCl}_{3} \cdot 6 \mathrm{H}_{2} \mathrm{O}$ solution and was incubated at RT for 10 minutes. The absorbance of the samples was measured at $415 \mathrm{~nm}$ using distilled water as a blank and the results were expressed in $\mu \mathrm{g}$ Quercetin equivalents per $100 \mathrm{~g}$ ( $\mu \mathrm{g} \mathrm{QE} / 100 \mathrm{~g})$.

2.7.2. Determination of Total Phenolic Content (TPC). $0.1 \mathrm{~mL}$ of the sample was mixed with $1.4 \mathrm{~mL}$ of $7.5 \%$ $\mathrm{Na}_{2} \mathrm{CO}_{3}$ and was incubated for 6 minutes. To the same solution, $1.5 \mathrm{~mL}$ of Folin-Ciocalteu reagent was added and incubated at RT for 60 minutes in a dark condition. The absorbance was measured at $765 \mathrm{~nm}$ using distilled water as a blank and the results were expressed in $\mathrm{g}$ gallic acid equivalents per $100 \mathrm{~g}$ (g GAE/100 g).

2.7.3. Determination of Total Antioxidant Capacity (TAC). TAC was evaluated using a phosphomolybdenum assay adapted from Biwas et al. [22] with modifications. The phosphomolybdenum reagent was prepared by mixing equivalent volumes of $28 \mathrm{mM}$ sodium sulphate and $4 \mathrm{mM}$ ammonium molybdate and $0.6 \mathrm{M}$ sulphuric acid. $3 \mathrm{~mL}$ of the sample was mixed with $1 \mathrm{~mL}$ of the phosphomolybdenum reagent, and the samples were incubated at $90^{\circ} \mathrm{C}$ for $90 \mathrm{~min}$. The absorbance was measured at $695 \mathrm{~nm}$ using distilled water as a blank and the results were expressed as g ascorbic acid equivalents per $100 \mathrm{~g}$ (g AAE/ $100 \mathrm{~g})$. 
2.7.4. Determination of Ferric Reducing Antioxidant Power (FRAP). The FRAP reagent was prepared by mixing $50 \mathrm{~mL}$ of $0.3 \mathrm{M}$ pH 3.6 acetate buffer, $5 \mathrm{~mL}$ of $10 \mathrm{mM}$ TPTZ solution prepared in $40 \mathrm{mM} \mathrm{HCl}$, and $5 \mathrm{~mL}$ of $20 \mathrm{mM} \mathrm{FeCl}_{3} \cdot 6 \mathrm{H}_{2} \mathrm{O}$ Solution. $100 \mu \mathrm{L}$ sample was mixed with $2.9 \mathrm{~mL}$ of FRAP reagent and the absorbance was measured at $593 \mathrm{~nm}$ using distilled water as a blank for every 1 minute.

2.7.5. Determination of 2, 2-Diphenyl-1-picrylhydrazyl (DPPH) Scavenging Activity. $1 \mathrm{~mL}$ of the sample was mixed with $2 \mathrm{~mL}$ of $0.004 \% \mathrm{DPPH}$ and was incubated for 30 minutes at RT. The absorbance was measured at $517 \mathrm{~nm}$ using methanol as a blank. The \%DPPH scavenging activity was calculated using the following equation:

$$
\text { Inhibition (\%) }=A_{\text {control }}-\frac{A_{\text {sample }}}{A_{\text {control }}} \times 100 \text {. }
$$

2.7.6. Determination of Median Inhibition Concentration (IC50). To $1 \mathrm{~mL}$ of series of five concentrations, $100 \%, 80 \%$, $60 \%, 40 \%$, and $20 \%$, which were prepared using the samples and distilled water, $2 \mathrm{~mL}$ of $0.004 \% \mathrm{DPPH}$ solution was added and was incubated for 30 mins at RT. The absorbance of all the samples was measured at $517 \mathrm{~nm}$ using methanol as a blank. The \% DPPH scavenging activity was calculated using equation (1).

2.8. Determination of the Antimicrobial Activity. The antimicrobial activity was determined using two types of bacterial strains Staphylococcus aureus and Escherichia coli using the agar well diffusion technique on Mueller-Hinton agar (MHA). The bacterial culture was evenly spread on the MHA plates using a cotton swab. Three wells were created on the MHA for the negative control (-) and the two replicates of the sample ( $S 1$ and $S 2$ ) as shown in Figure $7.1 \mathrm{~mL}$ of saline was added to the negative control (-) and $1 \mathrm{~mL}$ of sample was added to $S 1$ and $S 2$. Gentamycin discs were used as the positive control $(+)$. The plates were incubated at $37^{\circ} \mathrm{C}$ for 24 hours and the diameter of the zone of inhibition was measured using a ruler.

2.9. Statistical and Particle Size Analysis. $10 \mathrm{~mL}$ of PF AgNPs was centrifuged at $5000 \mathrm{rpm}$ for $10 \mathrm{~min}$ and were transferred to wash glass. The sample added to the watch glass was dried completely at $180^{\circ} \mathrm{C}$. The dried smear was dissolved by adding $200 \mu \mathrm{L}$ of distilled water and transferred into an Eppendorf tube. The sample was wrapped using aluminum foil and sent for the SEM analysis. The morphology of PF AgNPs was examined using a Scanning Electron Microscope and the average particle size was analyzed by the Malvern Zetasizer Nano ZS particle size analyzer from the Sri Lanka Institute of Nanotechnology (SLINTEC) using the Hitachi SU6600 SEM.

2.10. Determination of the Photocatalytic Activity. $1 \mathrm{~mL}$ of $5000 \mathrm{ppm}$ PF AgNPs and $1 \mathrm{~mL}$ of $0.2 \mathrm{M} \mathrm{NaBH}_{4}$ were added to $100 \mathrm{~mL}$ of $2 \mathrm{mM} \mathrm{MO}$. The absorbance of the reaction

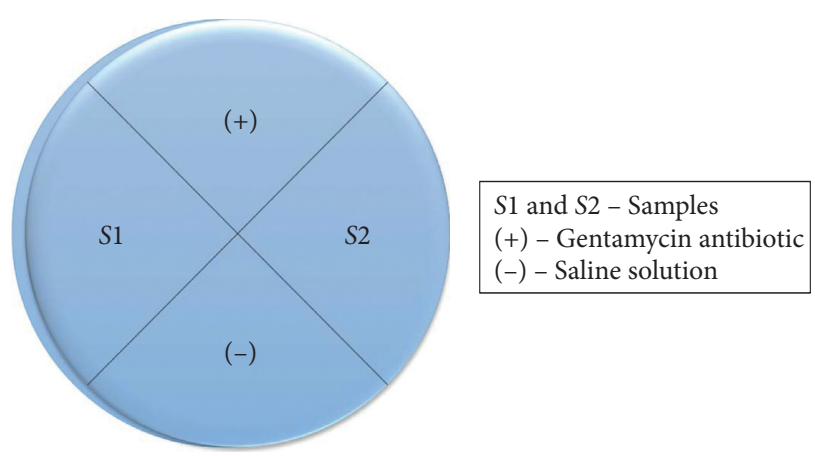

FIgUre 7: Illustration of the labeling of Petri plates.

mixture was measured from 300 to $560 \mathrm{~nm}$ using distilled water as a blank every 5 minutes for 20 minutes. The procedure was repeated for 333 ppm PF AgNPs.

\section{Results and Discussion}

3.1. Green Synthesis of AgNPs. In the preliminary stage, as the temperature is one of the key influence factors in the nanoparticle synthesis, the AgNPs synthesis was done at different temperatures keeping other parameters constant. The optimum condition for all the varieties was at room temperature for 3 days. This may be due to the slow formation and growth at room temperature which usually takes more hours to complete the bioreduction [23]. However, the synthesis at room temperature is greener than using heat, which is a further advantage. It was also observed that the AgNPs were stable even for more than 6 months stored at $4^{\circ} \mathrm{C}$. The formation of the AgNPs was initially observed by a color change to a reddish-brown solution (Figure 8). This is due to a phenomenon called the surface plasmon resonance (SPR) which occurs due to the excitation of the surface plasmons present on the outer surface of the AgNPs that get excited when light/UV is incident [24].

\subsection{Characterization of AgNPs}

3.2.1. UV-Visible Spectrophotometric Analysis. The absorption peaks at $440-500 \mathrm{~nm}$ (Figure 9) further confirmed the formation of AgNPs as they are known to exhibit a UV-Visible absorption peak in the range of $400-500 \mathrm{~nm}$ due to SPR [25].

3.2.2. SEM Analysis. The morphology of the PF AgNPs was observed by carrying out an SEM analysis which is a technique used to analyze the morphology. The results revealed that the PF AgNPs were spherical and around $30 \mathrm{~nm}$ in size (Figure 10).

3.3. Optical Properties of the AgNPs. Apart from the morphology, the optical properties of the synthesized AgNPs were analyzed by using UV-Visible absorbance spectra. Measuring the bandgap is an important parameter to characterize the conductivity of the nanoparticles. The bandgap is the energy difference between the top valence band (VB) and bottom of the conduction band (CB) and for an electron to move from 


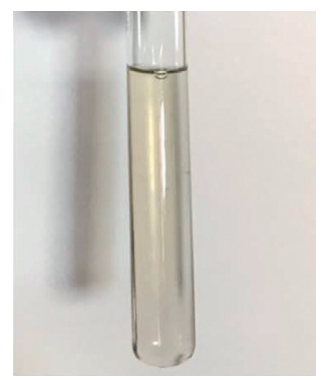

Light pink (LPF)

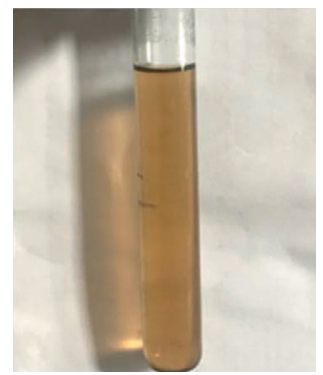

Light pink (LPF)

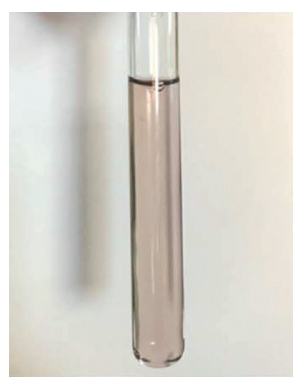

Red (RF)

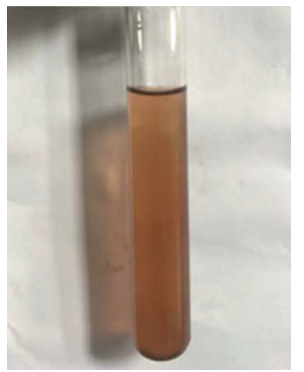

$\operatorname{Red}(\mathrm{RF})$

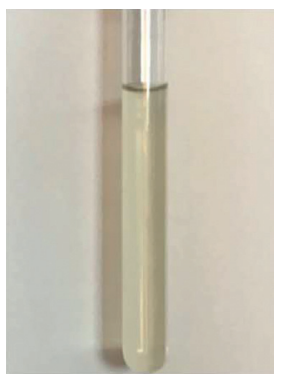

White pink dot (WPF)

(a)

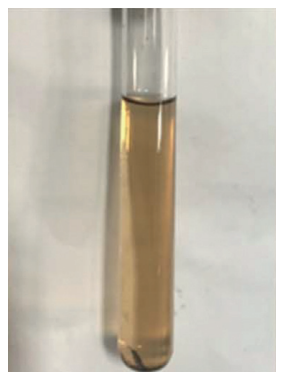

White pink dot (WPF)

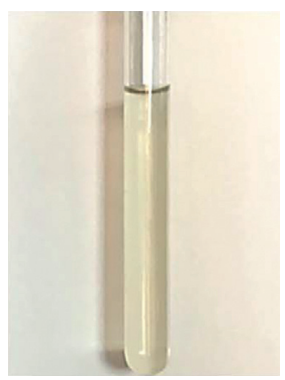

White yellow dot (WYF)

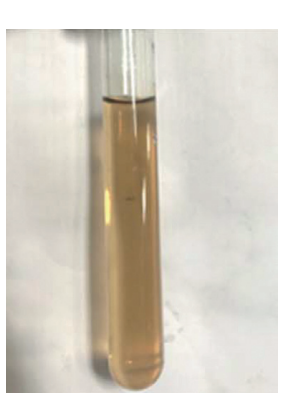

White yellow dot (WYF)

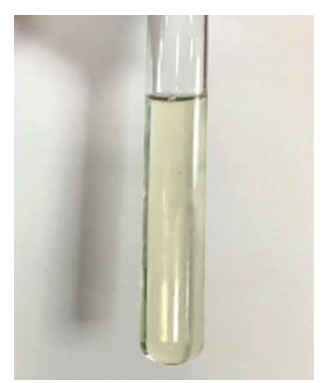

Purple flower (PF)

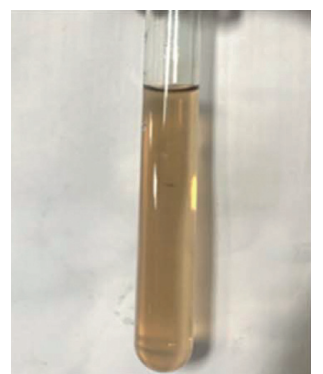

Purple flower (PF)

(b)

Figure 8: Green synthesis of AgNPs. (a) Flower extracts mixed with silver nitrate before 3 days and (b) after 3 days at RT.

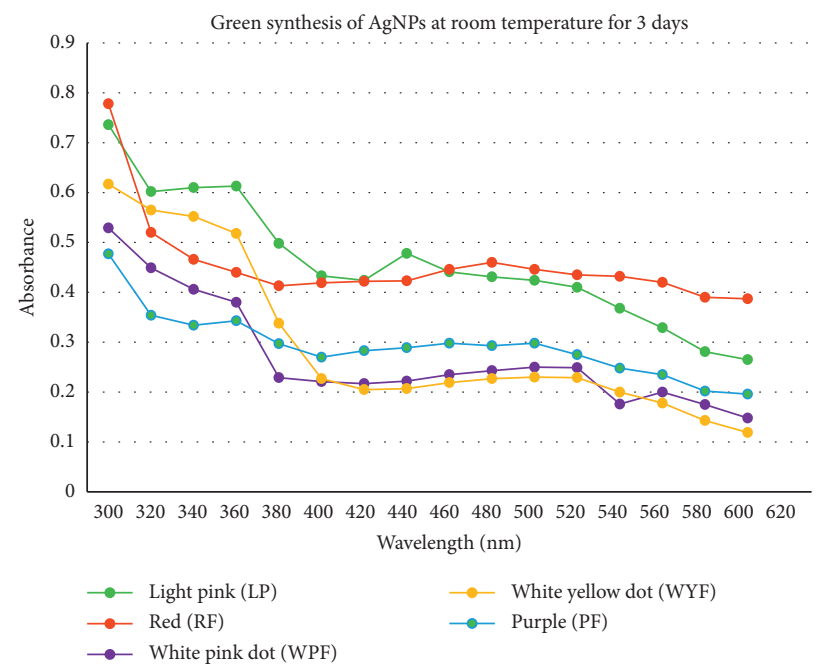

FIGURE 9: UV-Visible spectra of the synthesized AgNPs.

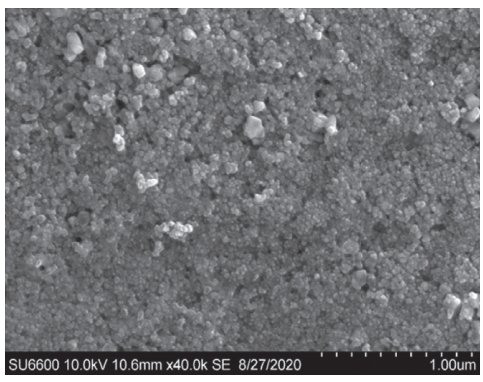

(a)

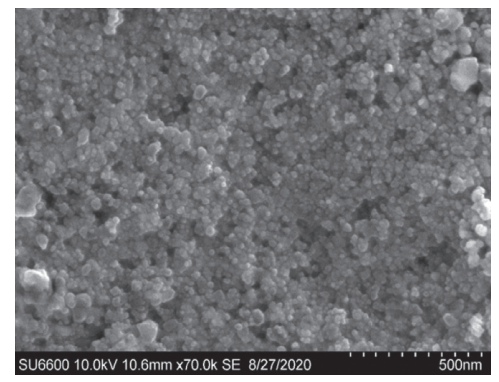

(b)

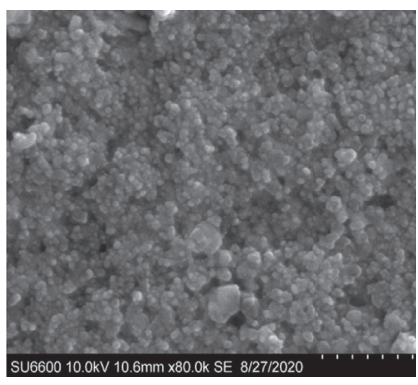

(c)

FIgURe 10: SEM image of the synthesized PF AgNPs. (a) x40 k/scale - $500 \mathrm{~nm}$; (b) x70 k/scale - $500 \mathrm{~nm}$; and (c) x80 k/scale - $500 \mathrm{~nm}$. 
the $\mathrm{VB}$ to the $\mathrm{CB}$, it requires a specific minimum amount of energy known as the bandgap energy based on the which nanoparticles can be classified as semiconductors $(<3 \mathrm{eV})$ or insulators $(>4 \mathrm{eV})$ [26]. The optical edge of LPF AgNPs was observed at $440 \mathrm{~nm}$ and the bandgap energy was calculated as $2.82 \mathrm{eV}$ and was classified as a semiconductor by using the following equation, where $h$ is the plank's constant $=6.626 \times$ $10^{-34} \mathrm{~J} \mathrm{~s}, \mathrm{C}$ is the speed of light $=3 \times 10^{8} \mathrm{~m} / \mathrm{s}$, and $\lambda$ is the cutoff wavelength of LPF AgNPs $=440 \times 10^{-9}$ :

$$
E=h \times \frac{C}{\lambda} \text {. }
$$

Based on the calculated bandgap energies, all the synthesized AgNPs were classified as semiconductors (Table 2). According to Singh, Goyal, and Devlal [27], the bandgap energy increases as the size of semiconductor nanoparticles decreases; therefore, it can be deduced that LPF and RF AgNPs are smaller in size compared to WPF, WYF, and PF AgNPs. According to the SEM analysis, PF AgNPs were around $30 \mathrm{~nm}$ (Figure 10). This concludes that LPF and RF AgNPs are less than $30 \mathrm{~nm}$ in size.

3.4. Phytochemical Analysis. Phytochemical analysis revealed the presence of antioxidants for the bioreduction which resulted in stable AgNPs (Table 3).

3.5. Determination of the Antioxidant Activity. Phenolics compounds are phytochemicals produced by all plant species which primarily act as antioxidants as they are effective as reducing agents, hydrogen atom donors, and singlet oxygen scavengers [28]. Flavonoids are the largest group of polyphenolic compounds. Studies indicated that various glycosylated flavonoids, mainly quercetin, isorhamnetin, and kaempferol derivatives were produced in different parts of the Catharanthus roses plant [29].

3.5.1. Total Flavonoid Content (TFC). The TFC was determined using the aluminum colorimetric method, where the $\mathrm{AlCl}_{3}$ ions form stable acid complexes with C-4 keto group or wither with C-5 or C-3 hydroxyl groups of flavonols and flavones with maximum absorption at $415 \mathrm{~nm}$. Moreover, it also produces acid-labile complexes with the orthodihydroxyl groups in the A- or B- ring of flavonoids. AgNPs contained a higher TFC compared to the water extracts in the following order: $\mathrm{WPF}=\mathrm{WYF}=\mathrm{PF}=\mathrm{LPF}>\mathrm{RF}$ (Figure 11).

3.5.2. Total Phenolic Content (TPC). TPC was determined using the Folin-Ciocalteu reagent method, where the phenolic compounds react with Folin-Ciocalteu reagent to form molybdenum and tungsten oxides in an alkaline solution which is blue [30]. AgNPs contained a higher TPC compared to the water extracts in the following order: LPF $>$ WPF $=$ $\mathrm{WYF}=\mathrm{PF}>\mathrm{RF}$ (Figure 12).

3.5.3. Total Antioxidant Capacity (TAC). TAC was measured using a phosphomolybdenum assay based on the
TABLE 2: Classification of the synthesized AgNPs based on bandgap energy.

\begin{tabular}{lcc}
\hline AgNPs sample & Bandgap energy $(\mathrm{eV})$ & Classification \\
\hline Light pink (LPF) & 2.82 & \\
Red (RF) & 2.58 & \\
White pink dot (WPF) & 2.48 & Semiconductors \\
White yellow dot (WYF) & 2.48 & \\
Purple (PF) & 2.48 & \\
\hline
\end{tabular}

reduction of Mo (VI) to Mo (V) using the electrons donated by antioxidants in the samples to form green phosphate or Mo (V) compounds with maximum absorption of $695 \mathrm{~nm}$. [31]. AgNPs contained a higher TAC compared to the water extracts in the following order: $\mathrm{RF}>\mathrm{LPF}=\mathrm{WPF}=\mathrm{WYF}>\mathrm{PF}$ (Figure 13).

3.5.4. Ferric Reducing Antioxidant Power (FRAP). To analyze the reducing power, FRAP assay was carried out based on the reduction of ferric tripyridyl triazine complex $\left(\mathrm{Fe}^{3+}-\mathrm{TPTZ}\right)$ to $\mathrm{Fe}^{2+}$-tripyridyl triazine, where a blue color compound is produced due to the electron donation by antioxidants at low $\mathrm{pH}$ [32]. All the AgNPs took the least time for the free radical scavenging activity compared to the water extracts (Figure 14). PF AgNPs had the highest free radical scavenging activity at 3 minutes followed by WPF $=\mathrm{WYF}=\mathrm{RF}>\mathrm{LPF}$ (Figure 15).

3.5.5. Determination of 2, 2-Diphenyl-1-picrylhydrazyl $(D P P H)$ Scavenging Activity. The DPPH radical savaging activity is evaluated based on the electron-donating property of the antioxidants to the nitrogen of the DPPH [33]. The odd electron of the nitrogen results in the color change from a purple color to colorless when it pairs up. AgNPs showed a higher \% DPPH scavenging activity compared to the water extracts in the following order: $\mathrm{LPF}=\mathrm{RF}=\mathrm{WPF}=\mathrm{PF}>\mathrm{WYF}$ (Figure 16). The reducing power and the electron-donating property revealed the presence of higher TFC in WPF and WYF.

3.5.6. Determination of the Half-Maximal Inhibitory Concentration (IC50). The IC50 of the water extracts and the AgNPs were calculated to determine the concentration of the sample required to inhibit 50\% of the radical (Figures 17 and 18). As shown in Table 4 the IC50 was lower in AgNPs compared to the water extracts. According to Perera and Kandiah [21], the TAC is inversely proportional to the IC50; this was also proved by the results obtained as RF AgNPs have the highest TAC and lowest IC50 (Table 4).

3.6. Statistical Analysis. The one-way ANOVA analysis indicated that there is a statistically significant difference between the water extracts and AgNPs TFC, TPC, and TAC as the $F$ value $>F$ crit and $P$ value $<0.05$.

A weak correlation was indicated between TAC and TFC assays when compared to the correlation between TAC and TPC assays (Figure 19). Since different phenolic compounds have different antioxidant activities based on their structure 
TABle 3: Phytochemical analysis test results.

\begin{tabular}{|c|c|c|c|c|c|c|}
\hline Phytochemical & $\begin{array}{l}\text { Light pink } \\
\text { (LPF) }\end{array}$ & $\operatorname{Red}(\mathrm{RF})$ & White pink dot (WPF) & $\begin{array}{l}\text { White yellow dot } \\
\text { (WYF) }\end{array}$ & Purple (PF) & $\begin{array}{l}\text { Positive result color } \\
\text { change }\end{array}$ \\
\hline Carbohydrate & $\checkmark$ & $\checkmark$ & $\checkmark$ & $\checkmark$ & $\checkmark$ & \\
\hline Tannins & $\checkmark$ & $x$ & $x$ & $x$ & $\checkmark$ & \\
\hline Saponins & $\checkmark$ & $\checkmark$ & $x$ & $\checkmark$ & $\checkmark$ & \\
\hline Terpenoids & $\checkmark$ & $\checkmark$ & $\checkmark$ & $\checkmark$ & $\checkmark$ & \\
\hline Anthraquinones & $x$ & $x$ & $x$ & $x$ & $x$ & - \\
\hline Steroids & $\checkmark$ & $\checkmark$ & $x$ & $x$ & $\checkmark$ & \\
\hline Proteins & $\checkmark$ & $\checkmark$ & $\checkmark$ & $\checkmark$ & $\checkmark$ & \\
\hline
\end{tabular}

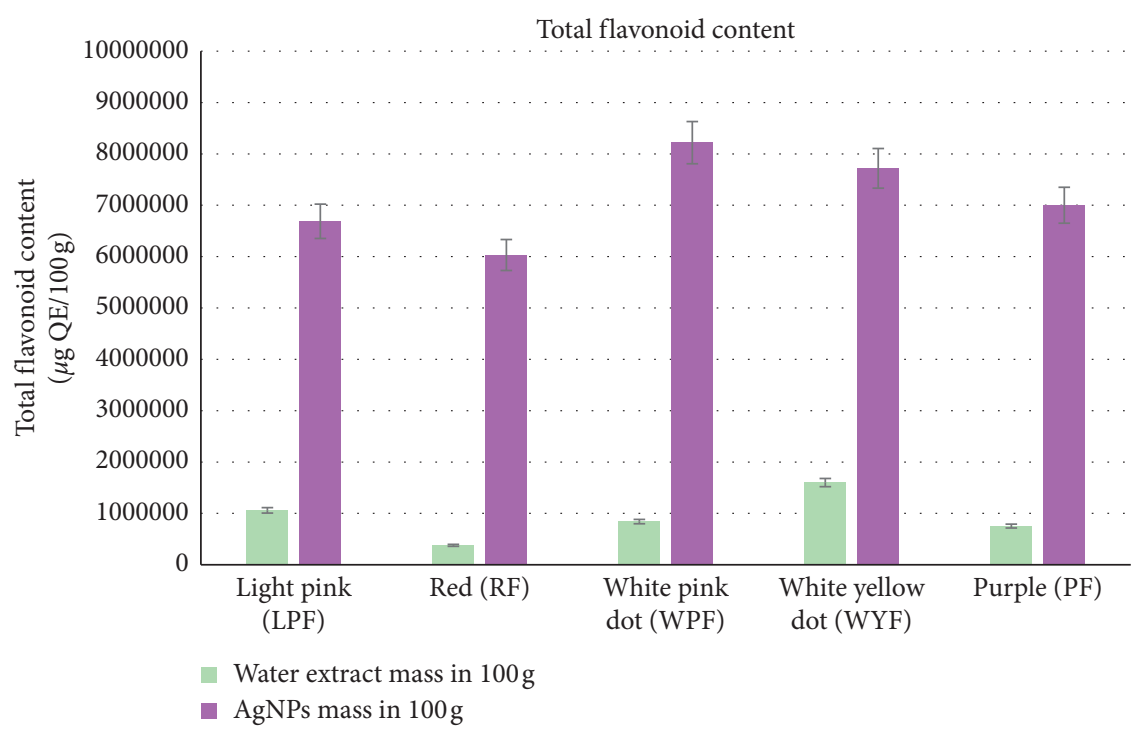

Figure 11: Total flavonoid content of water extracts and AgNPs expressed as quercetin equivalents (QE).

according to Kaur and Mondal [34], TAC could also be due to the presence of different types of various phenolic compounds as well as other phytochemicals such as pigments contributing to its antioxidant activity other than flavonoids. This could be also the reason RF AgNPs have the lowest TFC and TPC but show the highest antioxidant capacity. There is a strong correlation between DPPH and FRAP as both assays evaluate the efficiency of electron transference despite the different methods of elevation.
3.6.1. Determination of the Antimicrobial Activity. A higher antimicrobial activity against Escherichia coli was shown by AgNPs than that of water extracts in the following order: $\mathrm{RF}=\mathrm{WYF}>\mathrm{WPF}>\mathrm{PF}>\mathrm{LPF}$ (Figures 20 and 21). However, water extracts showed higher antimicrobial activity against Staphylococcus aureus than AgNPs (Figures 22 and 23). The higher antimicrobial activity of AgNPs against Escherichia coli compared to Staphylococcus aureus can be explained based on their differences in their cell wall. 


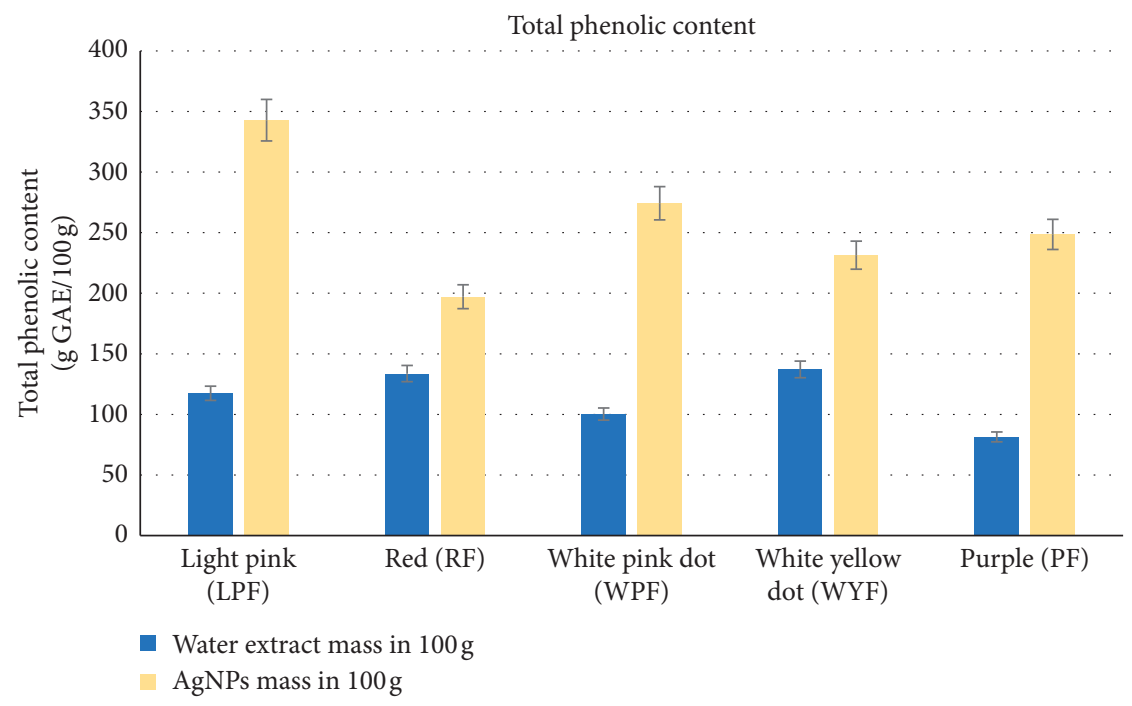

Figure 12: Total phenolic content of water extracts and AgNPs expressed as gallic acid equivalents (GAE).

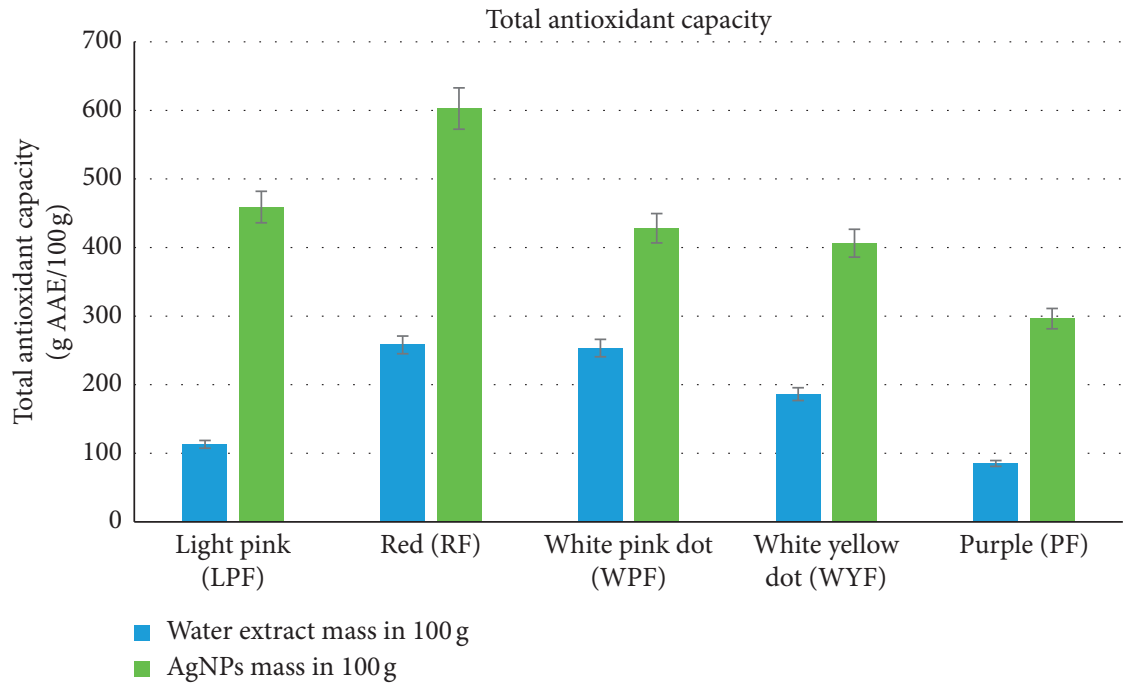

Figure 13: Total antioxidant capacity of water extracts and AgNPs expressed as ascorbic acid equivalents (AAE).

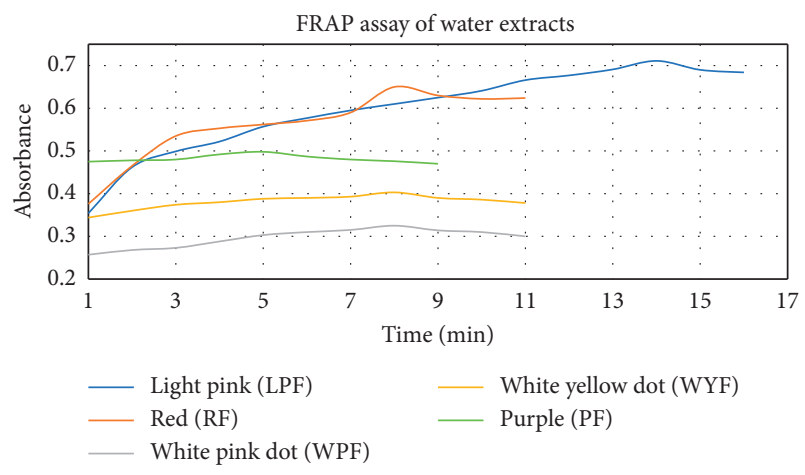

Figure 14: FRAP of the water extracts.

Escherichia coli possesses a thin peptidoglycan cell wall; therefore, the AgNPs can easily enter the bacteria through the cell wall unlike in Staphylococcus aureus [35]. Moreover, since the Staphylococcus aureus cell wall is negatively charged, it tends to bind with more $\mathrm{Ag}$ + lowering the interaction of AgNPs to the plasma membrane and protects it from ROS produced by AgNPs [36]. One-way ANOVA results indicated that there is no statistical significance between the antimicrobial activity of the water extracts and AgNPs against Staphylococcus aureus as the $F$ value $>F$ crit and $P$ value $<0.05$ and that there is a statistical significance between the antimicrobial activity of the water extracts and AgNPs against Escherichia coli as the $F$ value $>F$ and $P$ value $<0.05$.

3.6.2. Determination of the Photocatalytic Activity. Photocatalytic activity is the ability of AgNPs to catalyze a photoreaction under sunlight. When UV/visible light is incident onto the surface of AgNPs that fulfills the bandgap energy, electrons from the $\mathrm{CB}$ get excited to the $\mathrm{VB}$ and form electron pairs (Figure 24): 


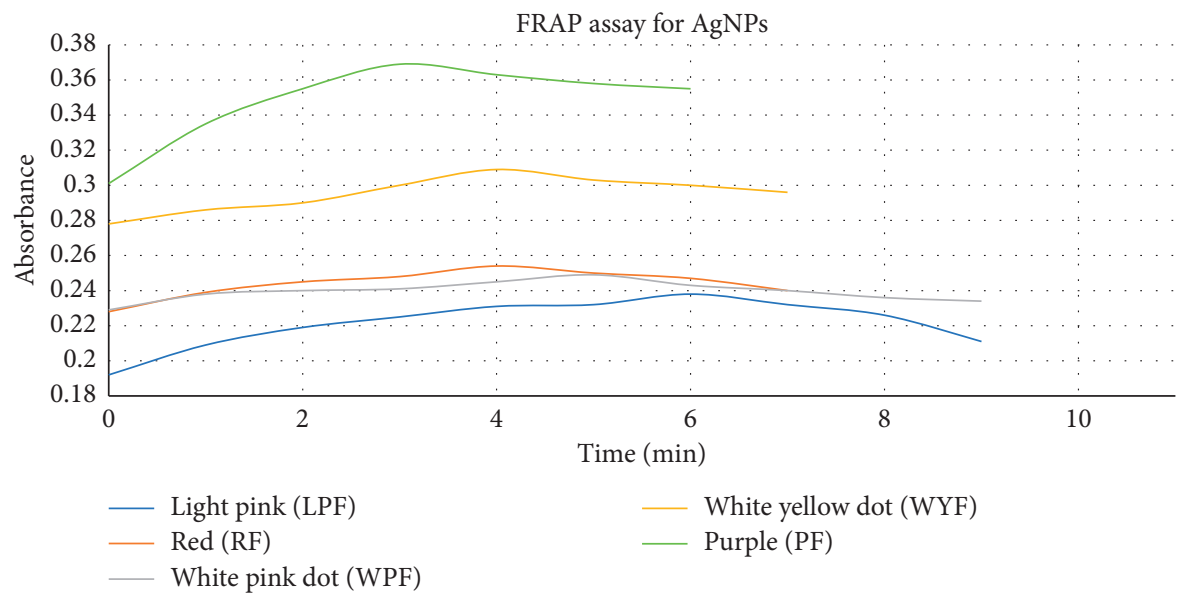

Figure 15: FRAP of the AgNPs.

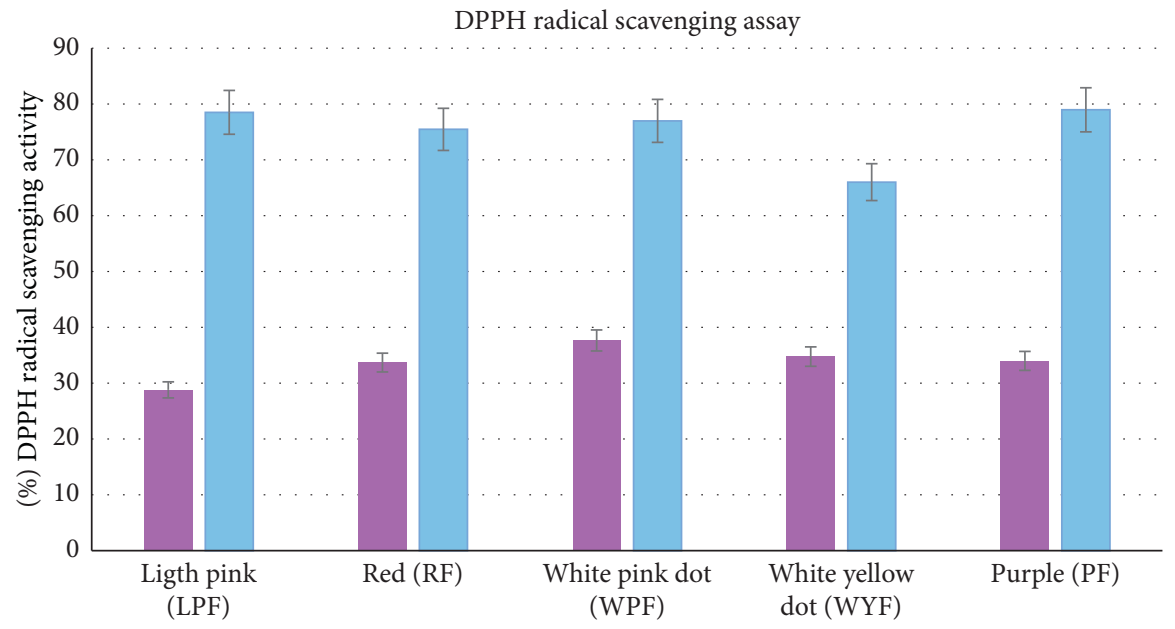

- (\%) DPPH of water extracts

(\%) DPPH of AgNPs

FiguRE 16: \% DPPH scavenging activity of water extracts and AgNPs.

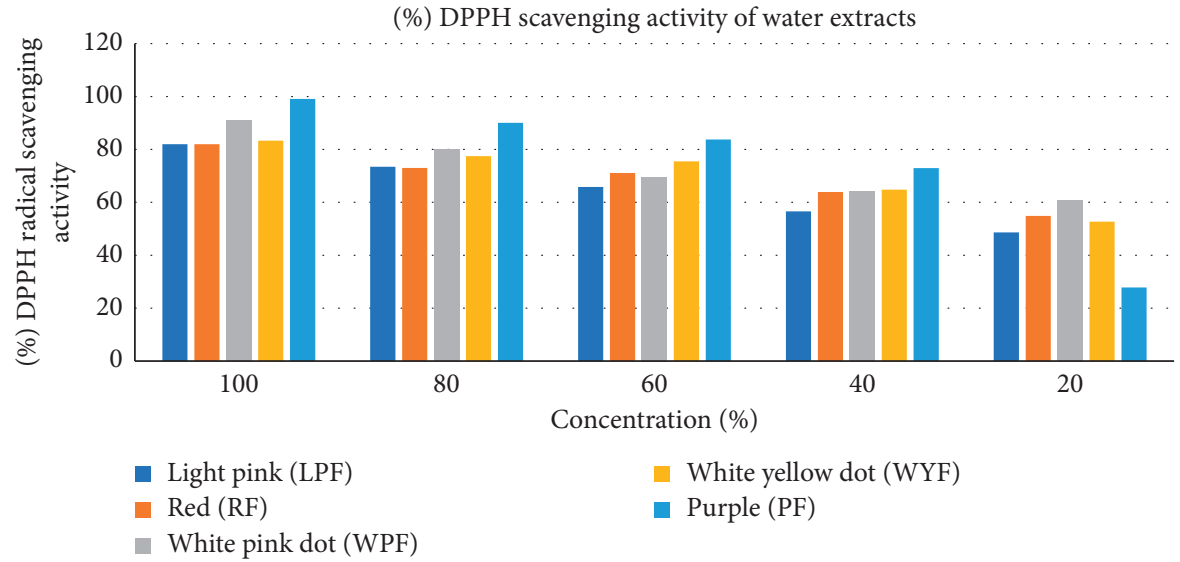

Figure 17: IC50 of the water extracts. 


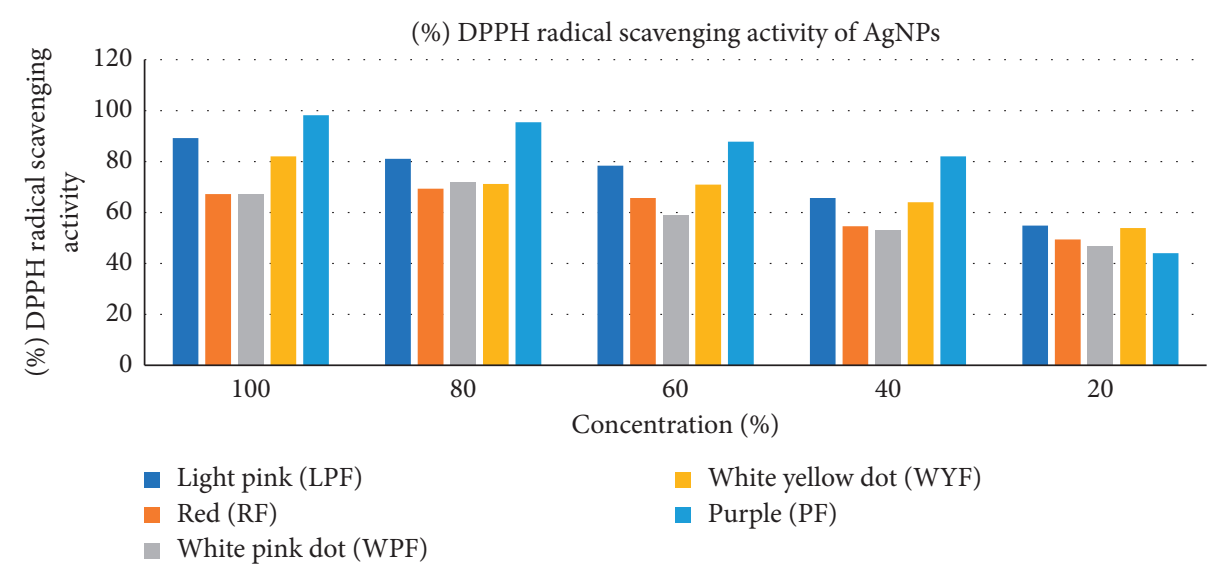

Figure 18: IC50 of the AgNPs.

TABLE 4: IC50 of water extracts and AgNPs.

\begin{tabular}{lcc}
\hline Sample & IC50 of water extracts & IC50 of AgNPs \\
\hline Light pink (LPF) & 23.37 & 3.23 \\
Red (RF) & 15.4 & 0.03 \\
White pink dot (WPF) & 27.84 & 0.12 \\
White yellow dot (WYF) & 3.15 & 2.04 \\
Purple (PF) & 29.04 & 8.23 \\
\hline
\end{tabular}

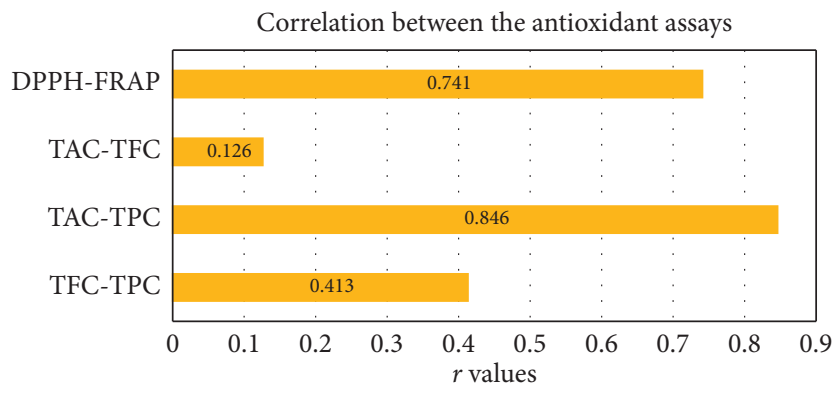

Figure 19: Correlation between antioxidant assays.

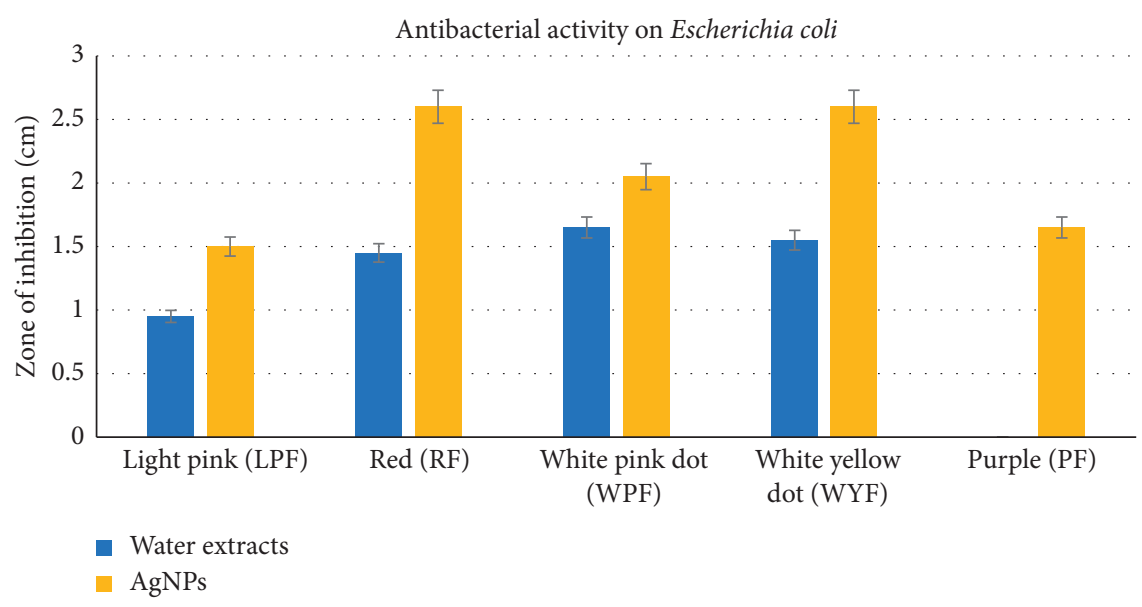

Figure 20: Antimicrobial activity of the water extracts and AgNPs against Escherichia coli. 


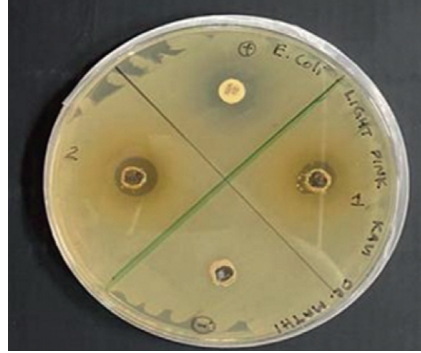

(a)

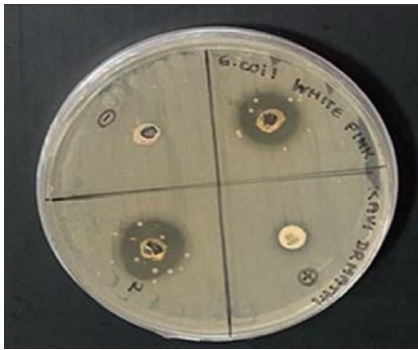

(e)

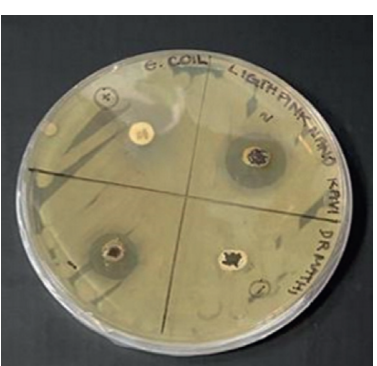

(b)

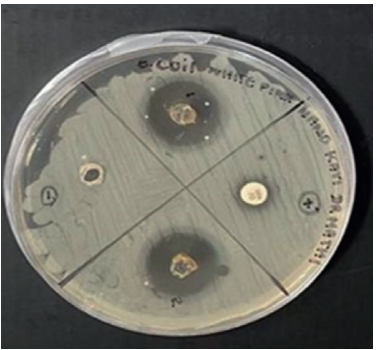

(f)

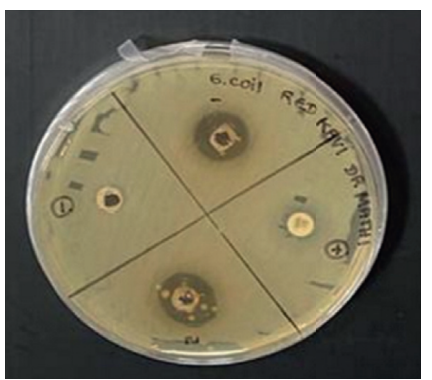

(i)

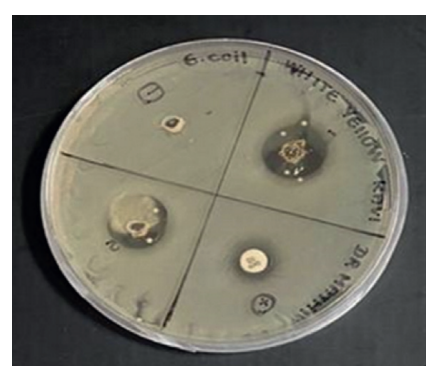

(c)

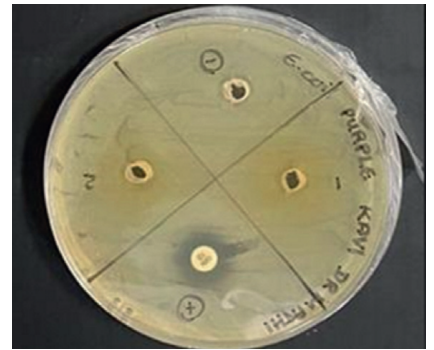

(g)

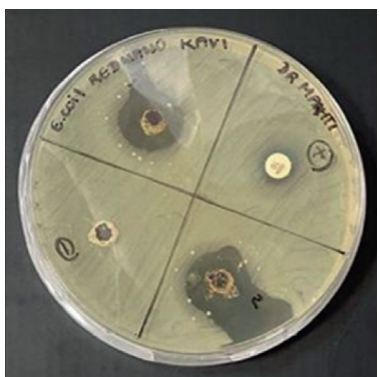

(j)

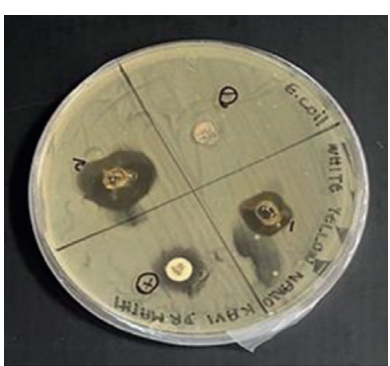

(d)

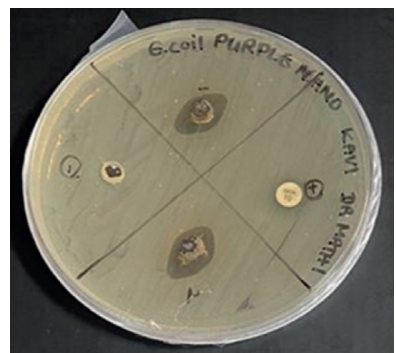

(h)

Figure 21: Antimicrobial activity of synthesized AgNPs and their respective flower extracts against Escherichia coli. (a) Light pink flower extract. (b) Light pink AgNPs. (c) White yellow flower extract. (d) White yellow AgNPs. (e) White pink flower extract. (f) White pink AgNPs. (g) Purple flower extract. (h) Purple AgNPs. (i) Red flower extract. (j) Red AgNPs.

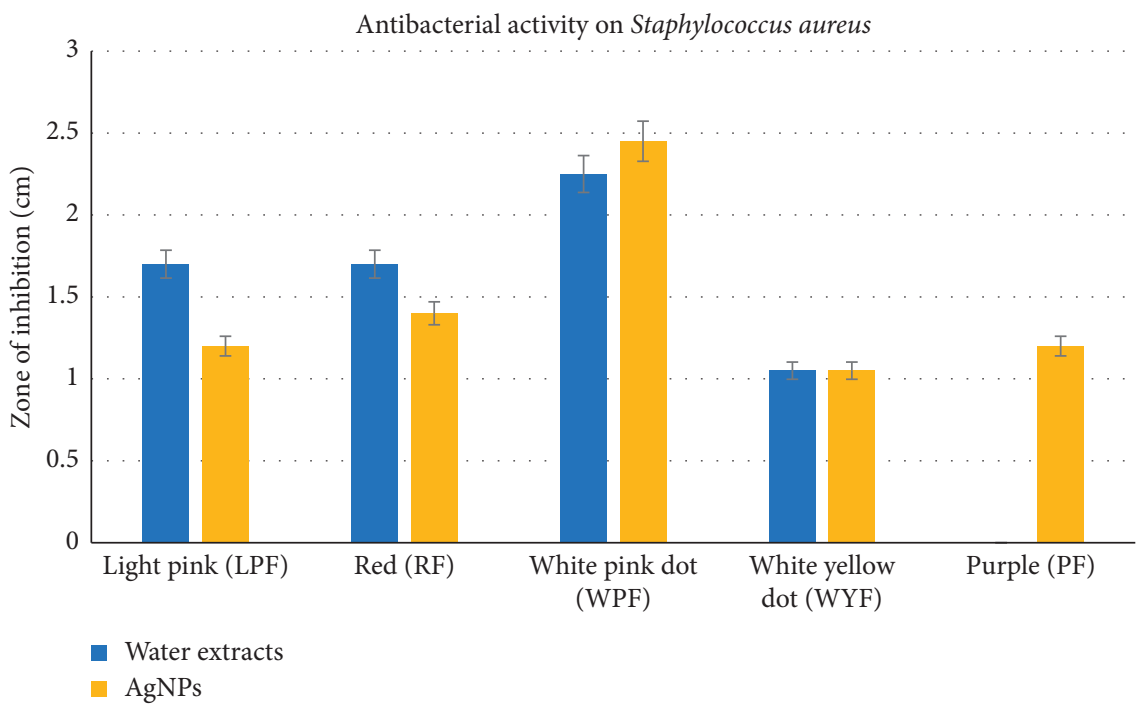

Figure 22: Antimicrobial activity of the water extracts and AgNPs against Staphylococcus aureus. 


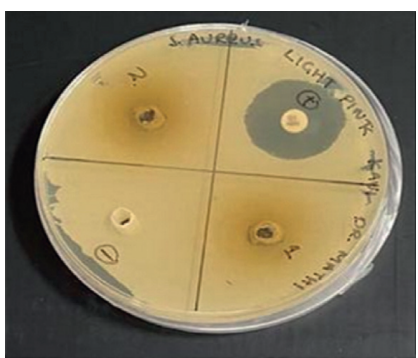

(a)

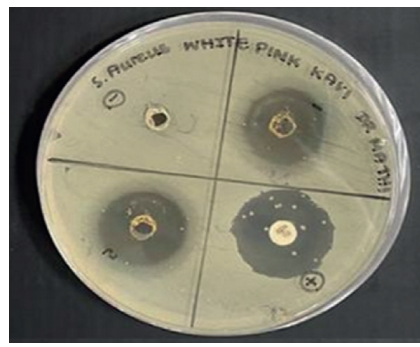

(e)

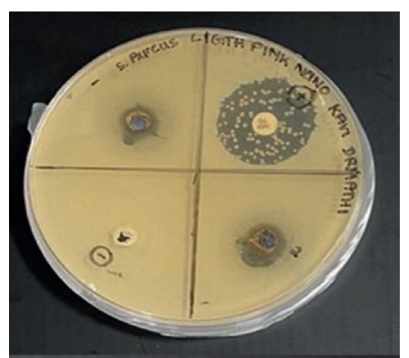

(b)

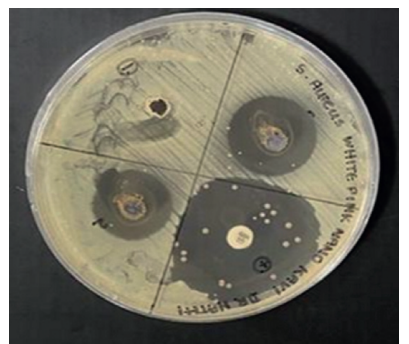

(f)

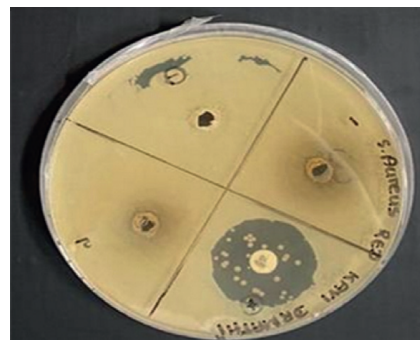

(i)

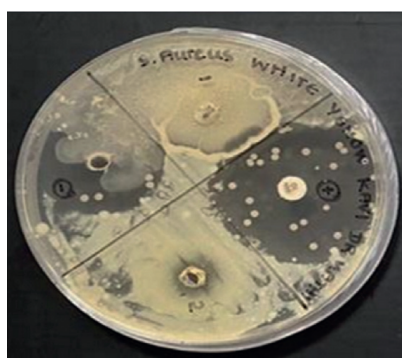

(c)

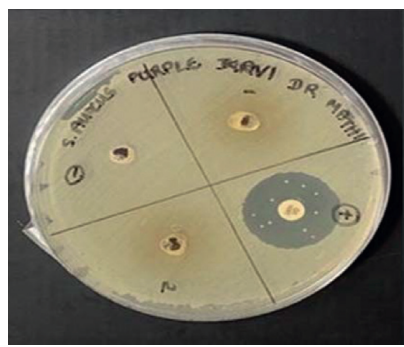

(g)

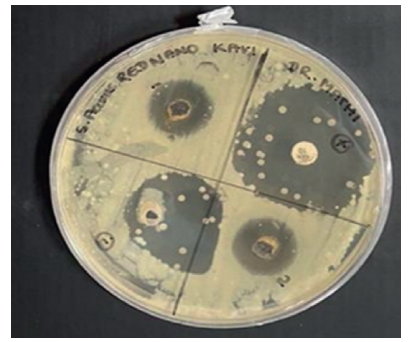

(j)

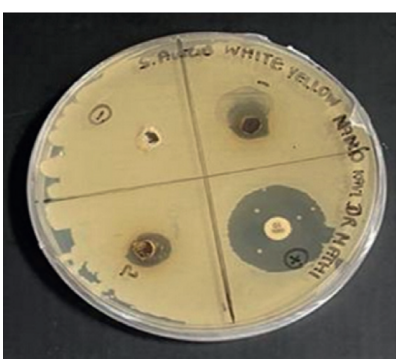

(d)

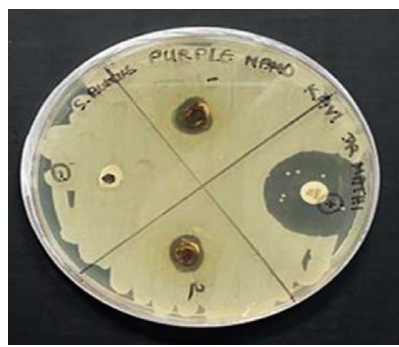

(h)

Figure 23: Antimicrobial activity of synthesized AgNPs and their respective flower extracts against Staphylococcus aureus. (a) Light pink flower extract. (b) Light pink AgNPs. (c) White yellow flower extract. (d) White yellow AgNPs. (e) White pink flower extract. (f) White pink AgNPs. (g) Purple flower extract. (h) Purple AgNPs. (i) Red flower extract. (j) Red AgNPs.

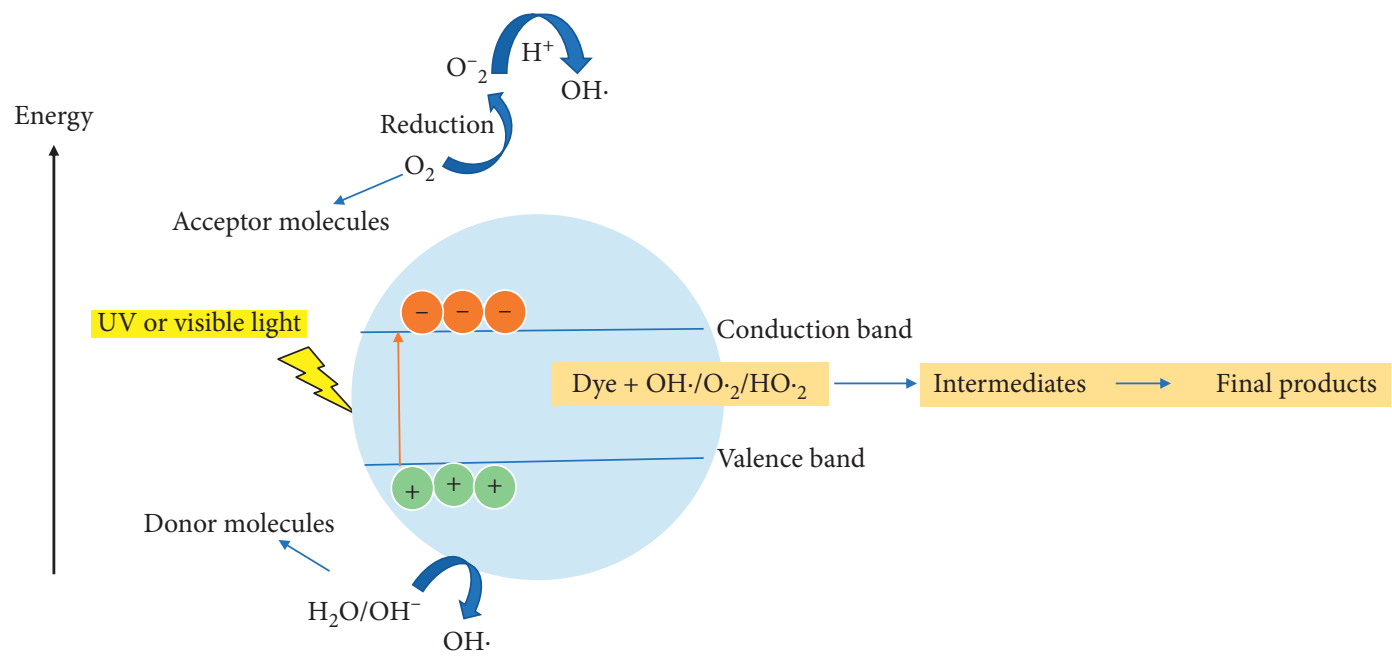

FIgUre 24: Mechanism of AgNPs photocatalysis [37].

$$
\operatorname{AgNPs}+\mathrm{hv} \longrightarrow\left(\mathrm{e}^{-}+\mathrm{h}^{+}\right)
$$

The holes $(\mathrm{H}+)$ and electrons produced by $\mathrm{VB}$ and $\mathrm{CB}$ react with $\mathrm{H}_{2} \mathrm{O}$ and $\mathrm{O}_{2}$, respectively, to form $\mathrm{OH}^{\bullet}, \mathrm{O}_{2}{ }^{\bullet-}$, and $\mathrm{HO}_{2} \bullet$ These produced radicles together attack the azo bond present in MO bringing about the degradation of the dyeforming intermediates and finally mineralize the dye to a colorless final product as shown in Figure 25. The role of $\mathrm{NaBH}_{4}$ is to produce $\mathrm{BH}_{4}{ }^{-1}$ which acts as an electron relay to provide AgNPs with more electrons to produce more 


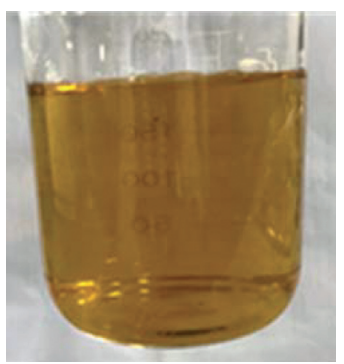

$0 \min$

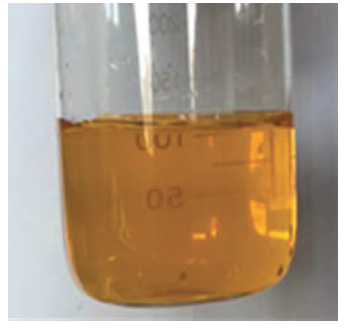

$0 \min$

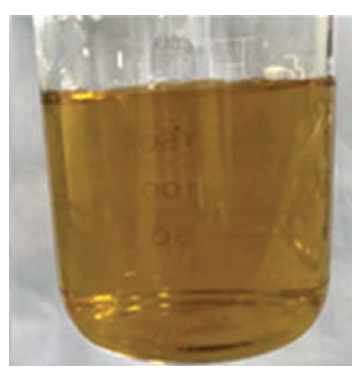

$5 \mathrm{~min}$

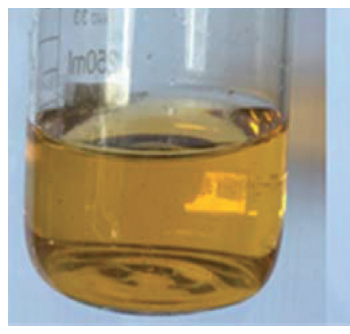

$5 \min$

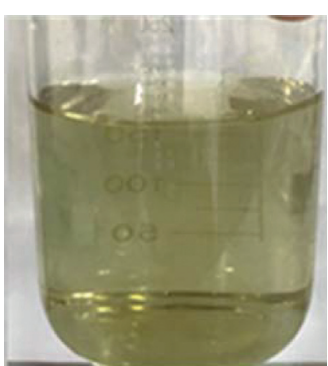

$10 \min$

(a)

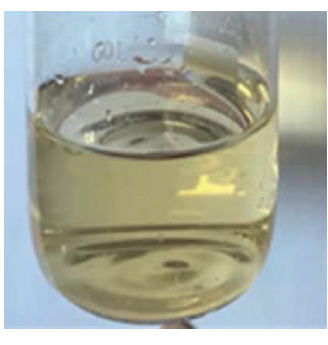

$10 \mathrm{~min}$

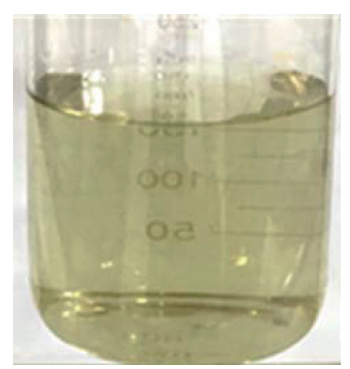

$20 \mathrm{~min}$

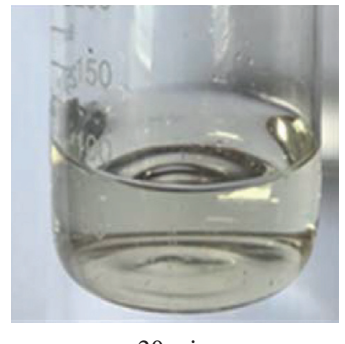

$20 \mathrm{~min}$

(b)

Figure 25: Decolorization of methyl orange from 0 to 20 minutes: (a) when 5000 ppm PF AgNPs and (b) 333 ppm PF AgNPs were added.

radicles which is why AgNPs have been reported to degrade organic dyes in a short period [37].

The methyl orange absorption peak at $460 \mathrm{~nm}$ was shown to be decreasing with time Figures 26 and 27. When $5000 \mathrm{ppm}$ PF AgNPs were used a blue shift of the methyl orange peak $(400 \mathrm{~nm})$ was observed as the degradation proceeded. Nagar and Devar [38] proposed degradation pathway could be due to the intermediates produced during the degradation as a result of successive demethylation where homolytic cleavage of nitrogen-carbon bond leads to the substitution of the methyl group by hydrogen (Figure 28).

3.6.3. Methyl Orange Peak. This shift was also observed using $333 \mathrm{ppm} \mathrm{PF}$ AgNPs and the degradation was completed in 20 minutes as the absorption of methyl orange was almost zero (Figure 28). The absence of the SPR peak of PF AgNPs $(500 \mathrm{~nm})$ can be due to the overlapping of the methyl orange peak or due to lack of homogeneity when the absorbance was measured as AgNPs tend sediment at the bottom of the beaker.

The kinetics of the methyl orange photocatalytic degradation was studied by plotting $\ln (\mathrm{Ct} / \mathrm{Co})$ against reaction time (Figures 29 and 30). According to the rate constant calculated from the gradients $5000 \mathrm{ppm} \mathrm{PF}$ AgNPs and $333 \mathrm{ppm}$ PF AgNPs were found to be 0.082 and 0.1136, respectively. Therefore, $333 \mathrm{ppm}$ PF AgNPs were proposed to have an efficient photocatalytic degradation ability compared to that of $5000 \mathrm{ppm}$ PF AgNPs.

The efficiency of photocatalytic degradation decreased when a higher concentration of PF AgNPs (5000 ppm) was used. According to Bansal and Sud, this might be due to the formation of intermediate moieties that can interfere with the degradation process [39].

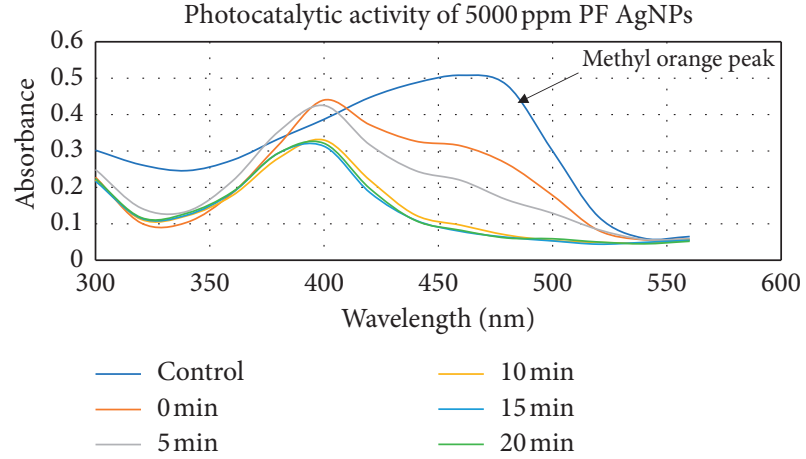

FIGURE 26: Absorbance of methyl orange with time when $5000 \mathrm{ppm}$ PF AgNPs were added.

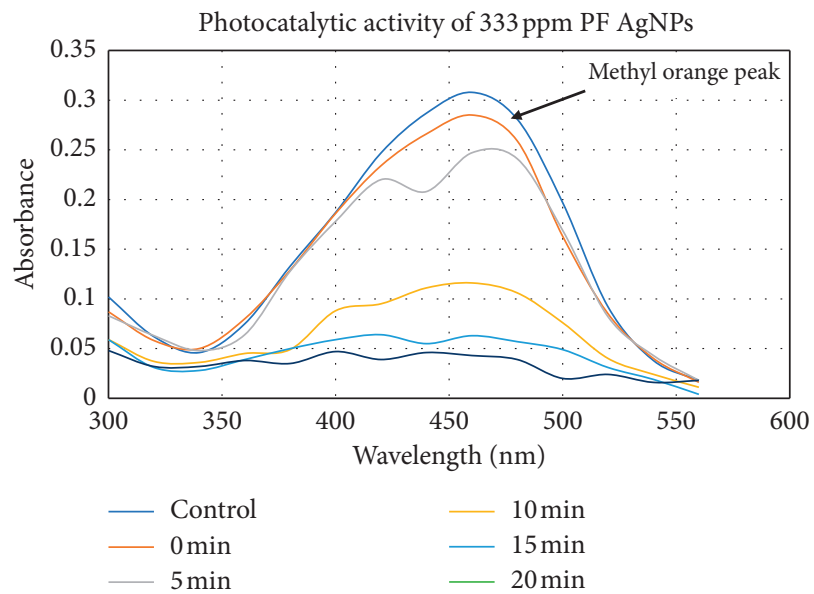

FIGURE 27: Absorbance of methyl orange with time when $333 \mathrm{ppm}$ PF AgNPs were added. 


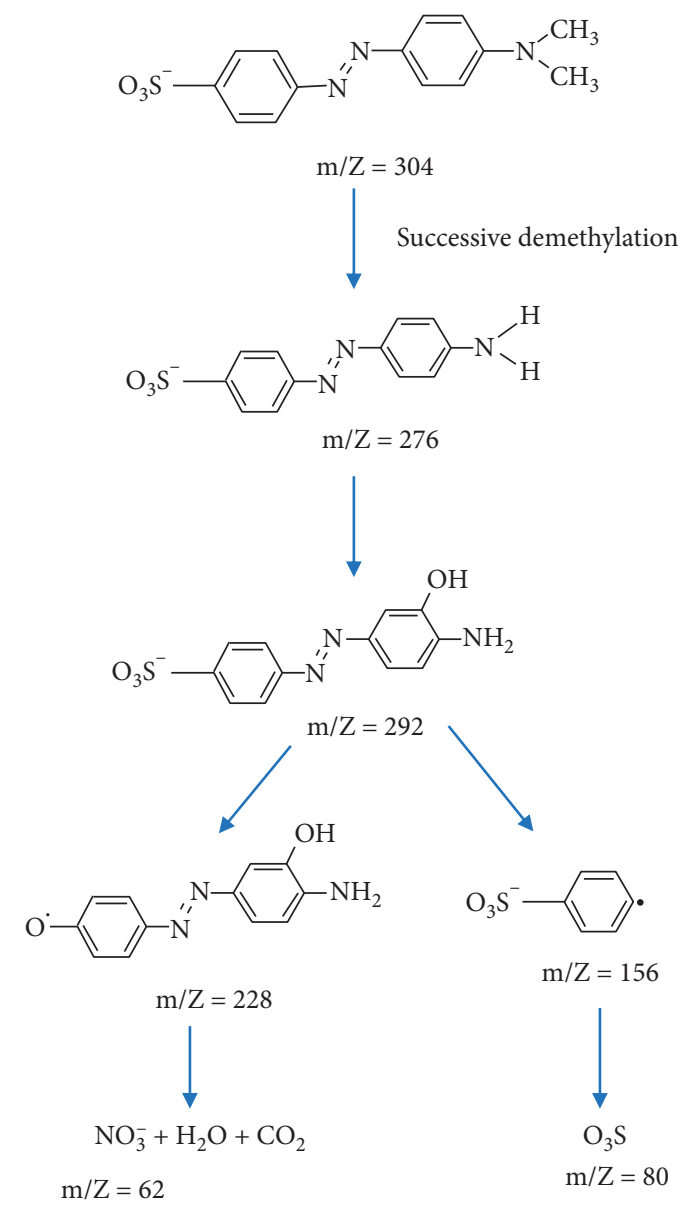

Figure 28: Proposed mechanism of methyl orange degradation according to Nagar and Devra, 2019.

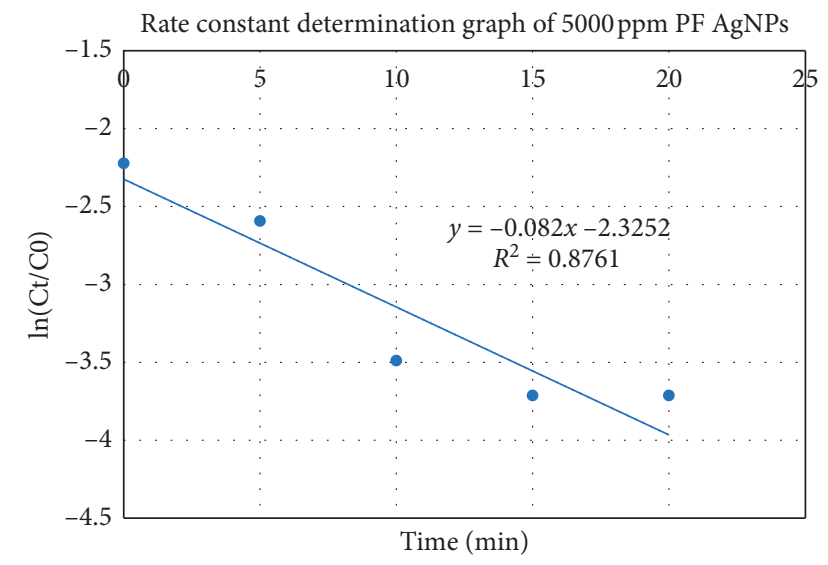

Figure 29: Rate constant graph of 5000 ppm PF AgNPs.

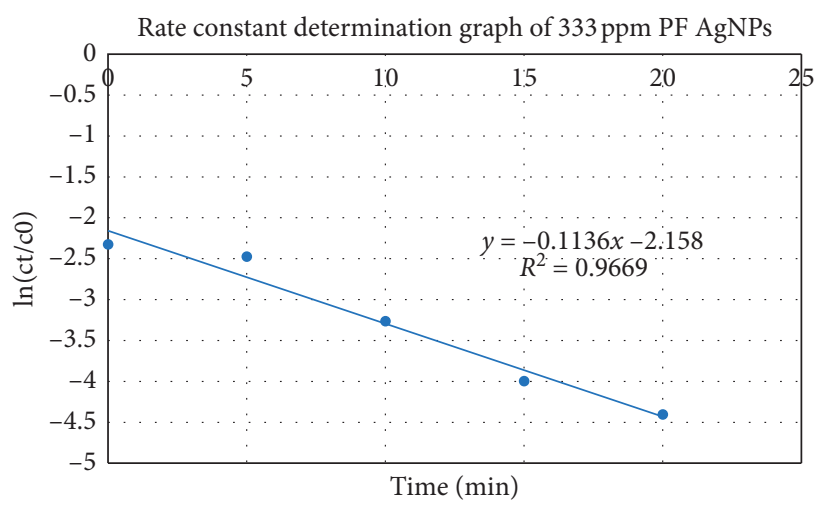

Figure 30: Rate constant graph of 333 ppm PF AgNPs.

\section{Conclusion}

In conclusion, the green synthesis of AgNPs from all six varieties of Catharanthus roseus was at RT for 3 days. SEM of the PF AgNPs and bandgap energies calculated revealed that all the synthesized AgNPs were found to be in the range of $0-30 \mathrm{~nm}$. The antioxidant assay results indicated that overall AgNPs show a higher antioxidant activity compared to their respective water extracts. Moreover, significant antimicrobial activity was shown by AgNPs against Escherichia coli compared to Staphylococcus aureus which concluded that the AgNPs were more effective against Gram-negative bacteria. The photocatalytic activity of 333 ppm PF AgNPs was found to be efficient for the photodegradation of methyl orange in 20 minutes compared to $5000 \mathrm{ppm}$ PF AgNPs. Since the synthesized AgNPs are ecofriendly and biocompatible, these AgNPs have the potential to offer their application in biomedical and related fields to improve the quality of life.

\section{Data Availability}

The data used to support the findings of this study are available from the corresponding author upon request.

\section{Conflicts of Interest}

The authors declare that there are no conflicts of interest regarding the publication of this paper.

\section{Acknowledgments}

The authors would like to acknowledge the Business Management School (BMS) for giving the opportunity to carry out an important project with available resources in the laboratory and the Sri Lanka Institute of Nanotechnology (SLINTEC) for allowing the use of the Hitachi SU6600 SEM. 


\section{References}

[1] S. Gurunathan, K. Kalishwaralal, R. Vaidyanathan et al., "Biosynthesis, purification, and characterization of silver nanoparticles using Escherichia coli," Colloids and Surfaces B: Biointerfaces, vol. 74, pp. 328-335, 2009.

[2] J. Singh, T. Dutta, K. Kim et al., "Green synthesis of metals and their oxide nanoparticles: applications for environmental remediation," Journal of Nanobiotechnology, vol. 16, p. 84, 2018.

[3] D. Williams, "The relationship between biomaterials and nanotechnology," Biomaterials, vol. 29, pp. 1737-1738, 2008.

[4] D. Bharathi and V. Bhuvaneshwari, "Evaluation of the cytotoxic and antioxidant activity of phyto-synthesized silver nanoparticles using Cassia angustifolia flowers," BioNanoScience, vol. 9, pp. 155-163, 2019.

[5] C. N. Nandana, M. Christeena, and D. Bharathi, "Synthesis and characterization of chitosan/silver nanocomposite using rutin for antibacterial, antioxidant and photocatalytic applications," Journal of Cluster Science, vol. 1, 2021.

[6] D. Bharathi, S. Vasantharaj, and V. Bhuvaneshwari, "Green synthesis of silver nanoparticles using Cordia dichotoma fruit extract and its enhanced antibacterial, anti-biofilm and photo catalytic activity," Materials Research Express, vol. 5, 2018.

[7] M. Jannathul Firdhouse and P. Lalitha, "Biosynthesis of silver nanoparticles and its applications," Journal of Nanotechnology, vol. 2015, Article ID 829526, 18 pages, 2015.

[8] X. F. Zhang, Z. G. Liu, W. Shen, and S. Gurunathan, "Silver Nanoparticles: Synthesis, characterization, properties, applications, and therapeutic approaches," International Journal of Molecular Sciences, vol. 17, pp. 2-3, 2016.

[9] P. Singh, Y. Kim, D. Zhang, and D. Yang, "Biological synthesis of nanoparticles from plants and microorganisms," Trends in Biotechnology, vol. 34, pp. 588-599, 2016.

[10] P. Kuppusamy, M. Yusoff, G. Maniam, and N. Govindan, "Biosynthesis of metallic nanoparticles using plant derivatives and their new avenues in pharmacological applications - an updated report," Saudi Pharmaceutical Journal, vol. 24, pp. 473-484, 2016.

[11] J. S. M Albert and T. M. Revathi, "Phytochemical analysis and Antioxidant activity of Catharanthus roseus Flower extract in different solvent," International Journal of Advanced Scientific Research and Management, vol. 1, p. 11, 2018.

[12] H. Jair, C. Reyes, I. Vásquez et al., "Alkaloids of pharmacological importance in Catharanthus Roseus," Alkaloids - Their Importance in Nature and Human Life, pp. 1-18, 2019.

[13] M. Faheem, S. Singh, B. S. Tanwer, M. Khan, and A. Shahzad, "In vitro Regeneration of multiplication shoots in Catharanthus roseus-an important medicinal plant," Advances in Applied Science Research, vol. 2, pp. 208-213, 2011.

[14] J. Aslam, H. K. Sheba, H. Z. Siddiqui et al., "An important drug: its applications and production," International Journal of Comprehensive Pharmacy, vol. 1, 2010.

[15] T. P. Devasagayam, J. C. Tilak, K. K. Boloor, K. S. Sane, S. S. Ghaskadbi, and R. D. Lele, "Free radicals and antioxidants in human health: current status and future prospects," Journal Association Physicians India, vol. 52, pp. 794-804, 2004.

[16] L. A. Pham-Huy, H. He, and C. Pham-Huy, "Free radicals, antioxidants in disease and health," International Journal of Biomedical Science, vol. 4, pp. 89-96, 2008.

[17] U. Nagaich, N. Gulati, and S. Chauhan, "Antioxidant and antibacterial potential of silver nanoparticles: biogenic synthesis utilizing apple extract," Journal of Pharmaceutics, vol. 2016, Article ID 7141523, 8 pages, 2016.

[18] G. Selvam and K. Sivakumar, "Photosynthesis of silver nanoparticles and photocatalytic degradation of methyl orange dye using silver (Ag) nanoparticles synthesized from Hypnea musciformis (Wulfen) J.V. Lamouroux," Applied Nanosciences, vol. 5, pp. 617-622, 2015.

[19] R. Comparelli, E. Fanizza, M. Curri et al., "UV-induced photocatalytic degradation of azo dyes by organic-capped $\mathrm{ZnO}$ nanocrystals immobilized onto substrates," Applied Catalysis B: Environmental, vol. 60, pp. 1-11, 2005.

[20] R. Roghini and K. Vijayalakshmi, "Phytochemical screening, quantitative analysis of flavonoids and minerals in ethanolic extract of Citrus paradise," International Journal Pharmaceutical Science and Research, vol. 9, pp. 4859-4864, 2018.

[21] B. Perera and M. Kandiah, "Microwave-assisted one-pot green synthesis of silver nanoparticles using leaf extracts from vigna unguiculate: evaluation of antioxidant and antimicrobial activities," International Journal of Multidisciplinary Studies, vol. 5, p. 62, 2018.

[22] D. Biswas and D. Bratati, "Antioxidant activity of some Indian medicinal plants used for the treatment of diabetes mellitus," Pharmacology, vol. 3, pp. 7-21, 2010.

[23] A. Dada, A. Inyinbor, E. Idu et al., "Effect of operational parameters, characterization and antibacterial studies of green synthesis of silver nanoparticles using Tithonia diversifolia," The Journal of Life and Environmental Sciences, vol. 6, 2018.

[24] S. Ahmed, M. Saifullah, B. L. Swami, and S. Ikram, "Green synthesis of silver nanoparticles using Azadirachta indica aqueous leaf extract," Journal of Radiation Research and Applied Sciences, vol. 9, pp. 1-7, 2016.

[25] J. Ashraf, M. Ansari, H. Khan, M. Alzohairy, and I. Choi, "Green synthesis of silver nanoparticles and characterization of their inhibitory effects on AGEs formation using biophysical techniques," Scientific Reports, vol. 6, p. 20414, 2016.

[26] D. Sundeep, T. Vijaya Kumar, P. S. S. Rao, R. V. S. S. N. Ravikumar, and A. Gopala Krishna, "Green synthesis and characterization of $\mathrm{Ag}$ nanoparticles from Mangifera indica leaves for dental restoration and antibacterial applications," Progress in Biomaterials, vol. 6, pp. 57-66.

[27] M. Singh, M. Goyal, and K. Devlal, "Size and shape effects on the band gap of semiconductor compound nanomaterials," Journal of Taibah University for Science, vol. 12, pp. 470-475, 2017.

[28] C. Sulaiman and I. Balachandran, "Total phenolics and total flavonoids in selected Indian medicinal plants," Indian Journal of Pharmaceutical Sciences, vol. 74, p. 258, 2012.

[29] D. Pereira, P. Valentão, M. Sottomayor, F. Ferreres, and P. Andrade, Phenolic Compounds in Catharanthus Roseus Natural Products, Springer, Berlin, Germany, 1st edition, 2013.

[30] T. Hatami, S. A. Emami, S. S. Miraghaee, and M. Mojarrab, "Total phenolic contents and antioxidant activities of different extracts and fractions from the aerial parts of artemisia biennis willd," Iranian Journal of Pharmaceutical Research, vol. 13, pp. 551-559, 2014.

[31] N. Saeed, M. R. Khan, and M. Shabbir, "Antioxidant activity, total phenolic and total flavonoid contents of whole plant extracts Torilis leptophylla L," BMC Complementary and Alternative Medicine, vol. 12, p. 221, 2012.

[32] M. El Jemli, R. Kamal, I. Marmouzi, A. Zerrouki, Y. Cherrah, and K. Alaoui, "Radical-scavenging activity and ferric reducing ability of juniperus thurifera(L.),J. oxycedrus(L. ),J. 
phoenicea(L.) andTetraclinis articulata(L.)," Advances in Pharmacological Sciences, vol. 1, pp. 2-3, 2016.

[33] H. Noreen, N. Semmar, M. Farman, and J. S. O. McCullagh, "Measurement of total phenolic content and antioxidant activity of aerial parts of medicinal plant Coronopus didymus," Asian Pacific Journal of Tropical Medicine, vol. 10, pp. 792-801, 2017.

[34] S. Kaur and P. Mondal, "Study of total phenolic and flavonoid content, antioxidant activity and antimicrobial properties of medicinal plants," Journal of Microbiology and Experimentation, vol. 1, pp. 23-28, 2014.

[35] D. Bharathi, M. Diviya Josebin, S. Vasantharaj, and V. Bhuvaneshwari, "Biosynthesis of silver nanoparticles using stem bark extracts of Diospyros Montana and their antioxidant and antibacterial activities," Journal of Nanostructures in Chemistry, vol. 8, pp. 83-92, 2018.

[36] M. Peiris, S. Fernando, P. Jayaweera, N. Arachchi, and T. Guansekara, "Comparison of antimicrobial properties of silver nanoparticles synthesized from selected bacteria," Indian Journal of Microbiology, vol. 58, pp. 301-311, 2018.

[37] R. Adam, G. Pozina, M. Willander, and O. Nur, "Synthesis of $\mathrm{ZnO}$ nanoparticles by co-precipitation method for solar driven photodegradation of Congo red dye at different $\mathrm{pH}$," Photonics and Nanostructures - Fundamentals and Applications, vol. 32, pp. 11-18, 2018.

[38] N. Nagar and V. Devra, "A kinetic study on the degradation and biodegradability of silver nanoparticles catalyzed Methyl Orange and textile effluents," Heliyon, vol. 5, pp. 13-56, 2019.

[39] P. Bansal and D. Sud, "Photodegradation of commercial dye, CI Reactive Blue 160 using $\mathrm{ZnO}$ nanopowder: degradation pathway and identification of intermediates by GC/MS," Separation and Purification Technology, vol. 85, pp. 112-119, 2012. 